\title{
Investigation on fatigue strength of cut edges produced by various cutting methods for high-strength steels
}

\author{
P. Diekhoff ${ }^{1}$ (I) $\cdot$ J. Hensel ${ }^{1} \cdot$ Th. Nitschke-Pagel ${ }^{1} \cdot$ K. Dilger $^{1}$
}

Received: 9 April 2019 / Accepted: 7 January 2020 / Published online: 28 January 2020

(C) The Author(s) 2020

\begin{abstract}
Due to the interest in effective light steel constructions, high-strength steels have gained importance. Different thermal cutting processes are frequently used in the metal processing industry. Besides the weld seams, free cutting edges gain technical and economic relevance as locations for potential fatigue cracks. In this investigation, fatigue tests were carried out on 8-mm-thick samples of S355M and S690Q steels at a stress ratio of $R=0.1$. The cutting methods used were oxygen, plasma, laser, and waterjet cutting. Quality improvement methods, like shot peening, grinding, and cutting speed reduction, were applied for some series. The surface roughness was measured to classify the specimens into quality groups according to ISO 9013. The cut edge condition was also characterized by hardness and residual stress measurements. The investigation shows that all tested series exceed the FAT100 class and can be classified in FAT125. Specimens ranged in quality group 2 of ISO 9013 according to the roughness achieve FAT140 regardless of cutting technology or material. According to the ISO 9013, most of the specimens are classified in the quality group 2 and group 3. Fatigue strength results are significantly different in one quality group. No prediction can be made. ISO 9013 has a weak connection to fatigue strength. Quality improvement methods have a significant influence on the fatigue strength and can increase it. Due to reduced cutting speeds, the roughness decreases also. It results in an increase of the fatigue strength in all tested series in this study. In order to make a prediction of the fatigue performance, the standard has to be specified and the cutting process as well as the steel strength should be considered.
\end{abstract}

Keywords Fatigue strength $\cdot$ Thermal cutting $\cdot$ Cut edge $\cdot$ High-strength steel $\cdot$ Surface quality $\cdot$ Hardness $\cdot$ Residual stresses $\cdot$ Posttreatment $\cdot$ Shot peening $\cdot$ Cutting speed

\begin{tabular}{ll}
\multicolumn{2}{l}{ Nomenclature } \\
CAL & Constant amplitude load \\
CEV & Carbon equivalent value \\
HAZ & Heat-affected zone \\
HV & Vickers hardness \\
$k$ & Slope $k$ of the S-N diagram \\
Log $C$ & Intercept of the S-N curve with the $y$-axis \\
$R$ & Stress ratio \\
$R_{\mathrm{a}}$ & Arithmetical average \\
$R_{\mathrm{eH}}$ & Yield strength \\
$R_{\mathrm{m}}$ & Tensile strength
\end{tabular}

Recommended for publication by Commission XIII - Fatigue of Welded Components and Structures

P. Diekhoff

p.diekhoff@tu-braunschweig.de

1 Institute of Joining and Welding, University of Braunschweig, Langer Kamp 8, D-38106 Brunswick, Germany
$R_{\max } \quad$ Maximum peak to valley height

$R_{\mathrm{z}}(\mu \mathrm{m}) \quad$ Average roughness

SD Standard deviation for $\log C$

$t$ (mm) Thickness specimens

UCI Ultrasonic contact impedance

XRD X-ray diffraction

\section{Introduction}

The fatigue strength reducing effects of weld seams is taken into account in the designing phase of welded constructions. Welds are placed in less stressed areas and conventional posttreatment methods, like shot peening, are used. Therefore, free cutting edges gain technical and economic relevance as locations for potential fatigue cracks.

Cutting technologies used in the industry produce different execution qualities at the cutting edge. The so-called Kitagawa diagram shows the relation between fatigue strength 
and defect size based on experimental values [1], as illustrated in Fig. 1. For components with sufficiently large defects, the fatigue strength of the component is characterized by crack propagation phase. With such defect sizes, the fatigue strength does not increase with the tensile strength. The execution quality of cut edges in terms of surface roughness (or "defect size") directly influences the local stress level and therefore the expected lifetime of the specimens. The lifetime is governed by crack growth in the case of large defects and by crack initiation in the case of small defects. Crack initiation is affected by the hardness respectively tensile strength resulting in an increase of fatigue strength with increasing tensile strength in the presence of small defects. A higher material strength therefore leads to a higher fatigue strength of the component due to the suppressed dislocation movement. In general, for thermal cutting edges, the fatigue strength should increase with tensile strength if the defect is smaller than the corresponding limit value.

The influence of thermal cutting edges and their different qualities on fatigue strength has already been analyzed in several studies, for example, by Sperle [1], Remes et al. [2], Stenberg et al. [3], and Lillemäe et al. [4]. Sperle carried out fatigue tests with a comprehensive range of steel grades (yield strengths from 240 to $900 \mathrm{MPa}$ ) on 6-mm-thick and 12-mmthick specimens. The specimens were thermally cut by gas, plasma, and laser. He found out that the fatigue strength increases with the steel grade depending on the surface roughness. The investigation compared also the plasma and laser cut edges with machined edges. Sperle determined that the fatigue strength rises with increasing tensile strength depending on the roughness. The increase of the fatigue strength in all cases is comparable, which was explained by the consistently small roughness depth.

Another study was made by Remes et al. [2]. They used 15mm-thick and 17-mm-thick specimens, which were plasma cut, and considered three series: first untreated, second ground, and third ground + sandblasted. The surface roughness, hardness, and residual stresses were determined out for the rolled plate surface and specimen cut edge. Fatigue tests on specimens were conducted, which had yield strengths of $460 \mathrm{MPa}$ or $690 \mathrm{MPa}$, with different surface treatments. The investigation shows that posttreatments increase the fatigue strength of high-strength steel due to the reduced surface roughness and induced compressive residual stresses. The study was continued by Lillemäe [4], which shows additionally that 690 steel had significantly higher fatigue strength compared with 355 steel. Stenberg et al. [3] investigated the influence of surface roughness on the fatigue strength in high-strength steels (S700 and S960) of 6-mm-thick and 16-mm-thick specimens. They were cut using oxygen, plasma, laser, and waterjet cutting. Surface roughness was measured and classified in the four quality groups according to the ISO 9013 standard [5] for thermal cutting quality tolerances as follows:
- Quality group 1: $R_{\mathrm{Z}}<14.8 \mu \mathrm{m}$,

- Quality group 2: $R_{Z}<46.8 \mu \mathrm{m}$,

- Quality group 3: $R_{Z}<79.6 \mu \mathrm{m}$,

- Quality group 4: $R_{\mathrm{Z}}<124.4 \mu \mathrm{m}$

It was used to assess the produced quality of the thermally cut edges. The testing proved an increased fatigue strength compared with the conservative international guidelines [6]. However, the examinations do not cover all quality ranges. At this point, the question arises, up to which conventional cutting edge quality fatigue strength increases with higher strength of material. The execution quality, for example, according to ISO 9013, of the material or different cutting processes in the guidelines is not considered yet [7,8]. Depending on the process and the cutting parameters used, cutting technologies produce different execution qualities at the cutting edge. The requirements for the quality characteristics of the components are, for instance, defined according to EN 1090 [9] and ISO 9013 respectively. Especially the surface roughness is a factor governing the fatigue strength of thermal cut edges.

In this investigation, fatigue tests were carried out on thermal cutting edges in different execution qualities with a constant force amplitude at a stress ratio $R=0.1$. The tested specimens were made from 8-mm-thick plates of S355M and S690Q. The cutting methods used were oxygen, plasma, laser, and waterjet cutting. Quality improvement methods, like shot peening, grinding, and cutting speed reduction, were applied. All samples were characterized in terms of hardness, roughness, and other quality characteristics according to EN 1090 and ISO 9013. Furthermore, the residual stresses were measured. The fatigue strength of all series was analyzed considering the surface quality characteristics.

\section{Experiment}

\subsection{Specimens}

Fatigue strength of different thermal cut edges of two different steel grades with a minimum yield strength of 355 and $690 \mathrm{MPa}$ was analyzed. The uniaxial test specimen used in this study was similar to previous work in [10] and is shown in Fig. 2. The samples were $394 \mathrm{~mm}$ long and $38 \mathrm{~mm}$ wide in the critical cross section. Besides the two different steel strengths, the specimens were cut from the 8-mm-thick plate using oxyfuel, plasma, laser, and waterjet cutting processes. The conditions for the specimens were untreated and defined "as-cut" and quality improvement treatments (posttreatment processes) such as grinding, sandblasting, and cutting speed reduction were used. The laser cutting process changed parameter from a $10-\mathrm{Hz}$ pulsed laser to continuous laser for both steel grades 


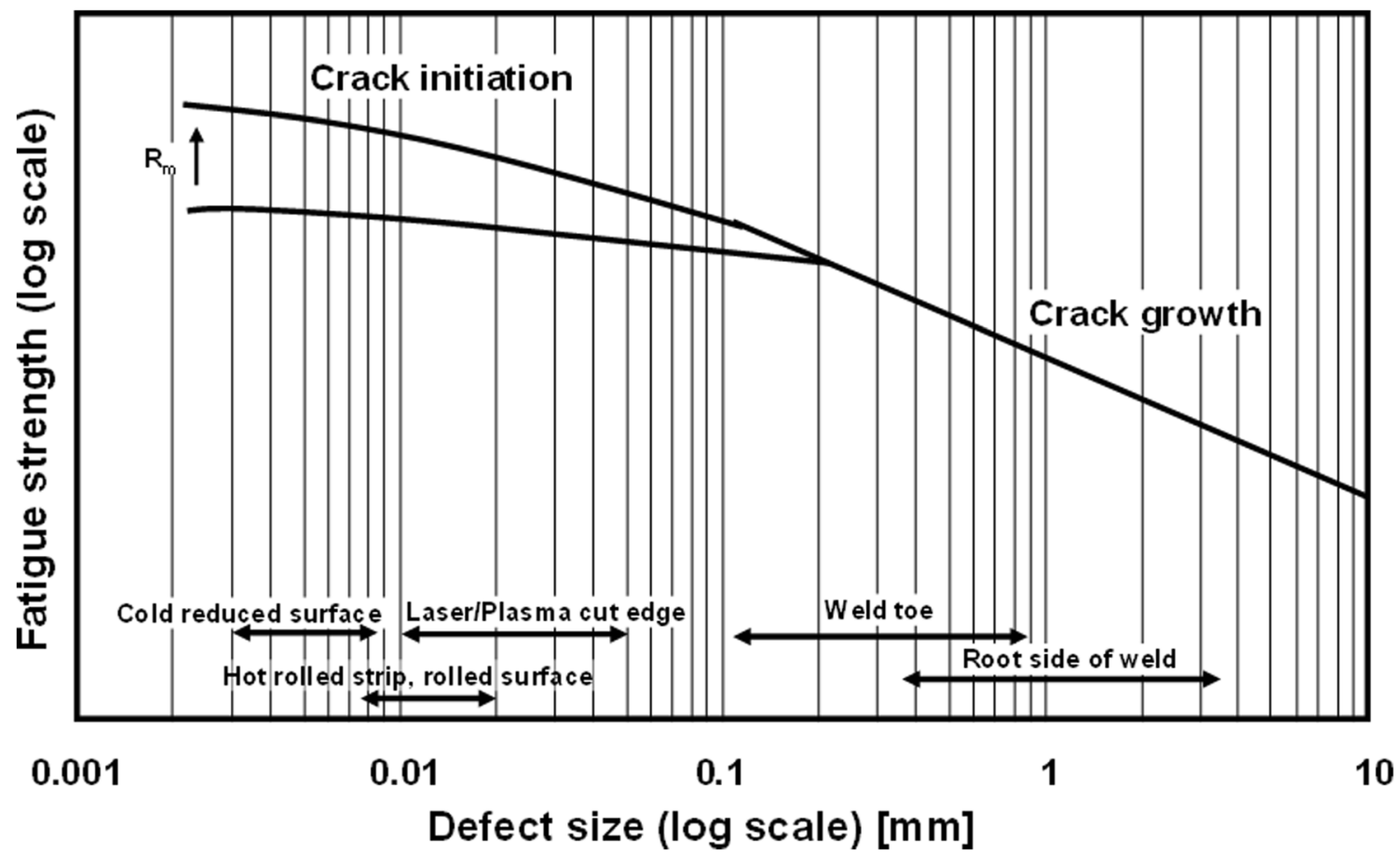

Fig. 1 Schematic Kitagawa diagram showing the influence of the defect size on fatigue strength of different steel strengths (according to Sperle [1])

(S355M, S690Q) using the reduced cutting speed. Fifteen different series were defined. A total amount of round more than 150 fatigue specimens were tested, which were at least 10 samples per test series.

The two different steel grades have a wide range of mechanical properties as follows:

- S355M: Thermomechanically rolled weldable fine grain structural steels with minimum yield strength of $355 \mathrm{MPa}$ and a carbon equivalent value (CEV) less than 0.39 , EN 10025-4 [11]. Samples were cut from an 8-mm-thick plate.

- S690Q: Quenched and tempered high-strength steel with a minimum yield strength of $690 \mathrm{MPa}$ and a carbon equivalent value less than 0.65 , EN 10025-5 [12]. Samples were cut from an 8 -mm-thick and 20 mm-thick plates.
Table 1 shows the detailed material properties. Because the specimens were cut from different industrial partners, two different charges of the materials were defined. The specimens using laser cutting processes were cut out of plates from charge 2 (S355M,2 and S690Q,2). The chemical composition including the carbon equivalent value is presented in Table 2 .

\subsection{Cut edge conditions}

The cut edge conditions were characterized. The location of measurements of the roughness, hardness, and residual stress is shown in Fig. 3. Hardness measurements were made at the cross section and directly at the cut edge (see below).

Table 3 shows the cut surface of steel S355M by using oxygen, plasma, laser, and waterjet cutting processes. The surface topography after using posttreatment methods like shot peening and grinding or due to speed reduction is also

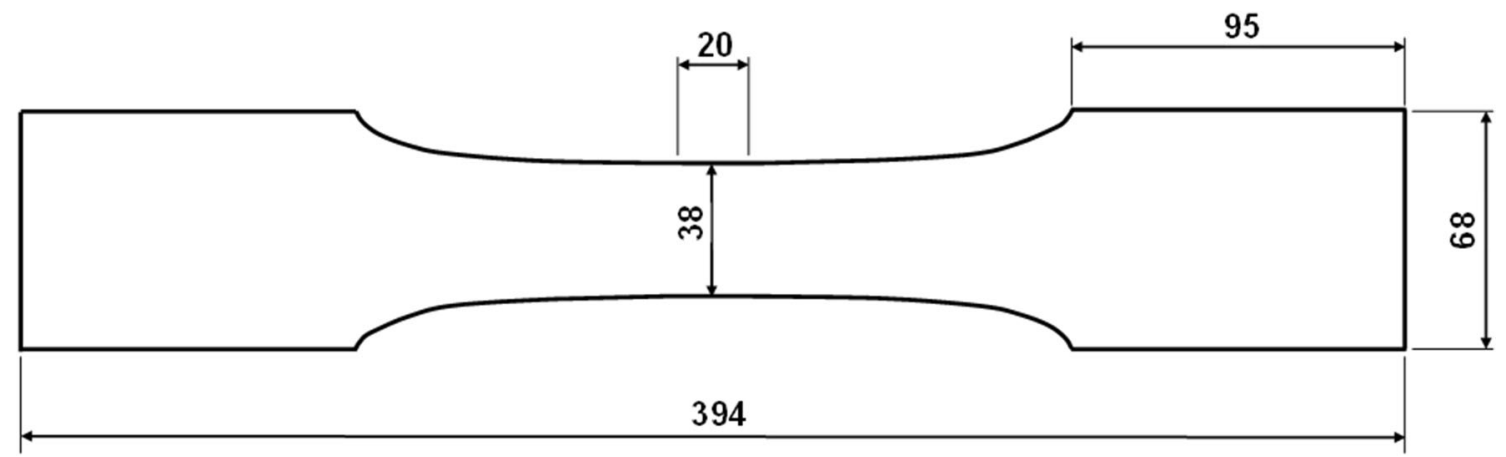

Fig. 2 Dimensions of the dog-bone specimen for fatigue test in millimeters 
Table 1 Material properties

\begin{tabular}{llll}
\hline Material & Yield strength $R_{\mathrm{eH}}(\mathrm{MPa})$ & Maximum tensile strength $R_{\mathrm{m}}(\mathrm{MPa})$ & Failure strain $(\%)$ \\
\hline S355M,1 (3 specimens tested) & $384-410$ & $480-509$ & $28-31$ \\
S355M,2 (3 specimens tested) & $435-446$ & $510-526$ & $28-30$ \\
S690Q,1 (3 specimens tested) & $804-836$ & $864-880$ & $14-15$ \\
S690Q,2 (3 specimens tested) & $755-765$ & $796-810$ & $17-19$ \\
\hline
\end{tabular}

shown. At the top of each figure, there is the upper edge, and at the bottom, there is the lower edge of the cut surface. It can be seen that oxygen cutting implicates a lot of slag and scale, which stick to the edge. It provides a cut surface with varying roughness. Plasma cutting creates the cut surface with the lowest roughness, while laser cutting generates surfaces with the highest roughness value. However, it depends on the cutting speed. The surface after shot peening and grinding looks visually clean. No other defects on the surfaces are visible.

\subsubsection{Roughness measurements}

Surface roughness measurements were made on the specimens according to ISO 4288 [13]. Measurements were done on the cut edge surface (Fig. 3). The tests were carried out with the MarSurf M 400 surface measuring instrument using the profile method over the length of $17.5 \mathrm{~mm}$. From each series, 3 specimens were measured: 3 lines at the top and 3 lines at the bottom of the cut edge surface. The following parameters were determined: The average of the five highest peaks and lowest valleys $R_{\mathrm{z}}$, the arithmetical average $R_{\mathrm{a}}$, and the maximum peak to valley height $R_{\max }$. No measurements were done at the plate surface.

\subsubsection{Hardness measurements and metallography analysis}

Cross sections have been cut from the dog-bone specimens by using a water-cooled abrasive cutter. The surface were ground using different abrasive paper, polished and etched with a Nital solution (2\%) to visual the microstructure. The hardness in the heat-affected zone (HAZ) of thermally cut edges was analyzed afterwards. Therefore, Vickers hardness (HV0.1) measurements were made for each series according to ISO 6507 [14]. The investigation was carried out with Wilson Hardness Tukon 1202 instrument. No hardness measurements were made for waterjet cut plates, because no changes to the base material were expected. Additionally the hardness was measured directly at the cut edge according to the instruction from the Appendix in the DIN EN 1090-2:2017 draft. UCI (ultrasonic contact impedance) method was used [15]. Cut edges have to be prepared and ground using a P600 abrasive paper. Valleys of the surface should be visible. Measurements are made as seen in Fig. 4.

\subsubsection{Residual stress measurements}

The residual stresses were measured on the cut edge of all series using the X-ray diffraction (XRD) technique. Location of the measurements which were in the middle of the cut edge is shown in Fig. 3. For the XRD experiments, a $\psi$ diffractometer with radiation source $\mathrm{CrK} \alpha$ was used. The circular collimator diameter was $1.5 \mathrm{~mm}$. The longitudinal residual stresses were calculated from the $\{211\}$-Fe diffraction lines determined at $13 \psi$-angles with help of the $\sin ^{2} \psi$-method. Residual stress measurements were done on all 15 different series.

\subsection{Fatigue tests}

All fatigue tests were performed on a $250-\mathrm{kN}$ hydraulic testing machine using cyclic tensile tests with a constant amplitude load (CAL) and a stress ratio $R=0.1$ following the recommendations of DIN 50100 [16]. The test frequency was 10-20 Hz, depending on the load level of each test. The main fatigue strength was determined in the life range of $1 \times 10^{5}$ to $2 \times$ $10^{6}$ cycles. The run-out point was defined at five million cycles and run-out specimens were excluded from the S-N curve calculation. The tests were stopped after complete failure of the specimen. The fracture surface was analyzed to identify the location of crack initiation (Table 4).

Table 2 Chemical composition (\%)

\begin{tabular}{lllllllllllllllll}
\hline Material & $\mathrm{C}$ & $\mathrm{Mn}$ & $\mathrm{Si}$ & $\mathrm{P}$ & $\mathrm{S}$ & $\mathrm{Cu}$ & $\mathrm{Ni}$ & $\mathrm{Cr}$ & $\mathrm{Mo}$ & $\mathrm{V}$ & $\mathrm{Ti}$ & $\mathrm{Al}$ & $\mathrm{N}$ & $\mathrm{Nb}$ & $\mathrm{CEV}$ \\
\hline $\mathrm{S} 355 \mathrm{M}, 1$ & 0.07 & 1.27 & 0.01 & 0.01 & 0.01 & 0.02 & 0.012 & 0.015 & 0.004 & 0.01 & 0.001 & 0.05 & 0.004 & 0.02 & 0.284 \\
$\mathrm{~S} 355 \mathrm{M}, 2$ & 0.06 & 0.74 & 0.02 & 0.01 & 0.004 & 0.01 & 0.015 & 0.035 & 0.005 & 0.001 & 0.001 & 0.03 & 0.004 & 0.03 & 0.191 \\
$\mathrm{~S} 690 \mathrm{Q}, 1$ & 0.09 & 1.03 & 0.2 & 0.01 & 0.003 & 0.02 & 0.03 & 0.313 & 0.194 & 0.001 & 0.003 & 0.1 & 0.004 & 0.03 & 0.367 \\
$\mathrm{~S} 690 \mathrm{Q}, 2$ & 0.10 & 1.36 & 0.29 & 0.01 & 0.003 & 0.03 & 0.037 & 0.023 & 0.012 & 0.001 & 0.003 & 0.07 & 0.004 & 0.02 & 0.342 \\
\hline
\end{tabular}




\section{". - Hardness measurement \\ $\diamond$ Residual stress \\ -. - Roughness measurement}

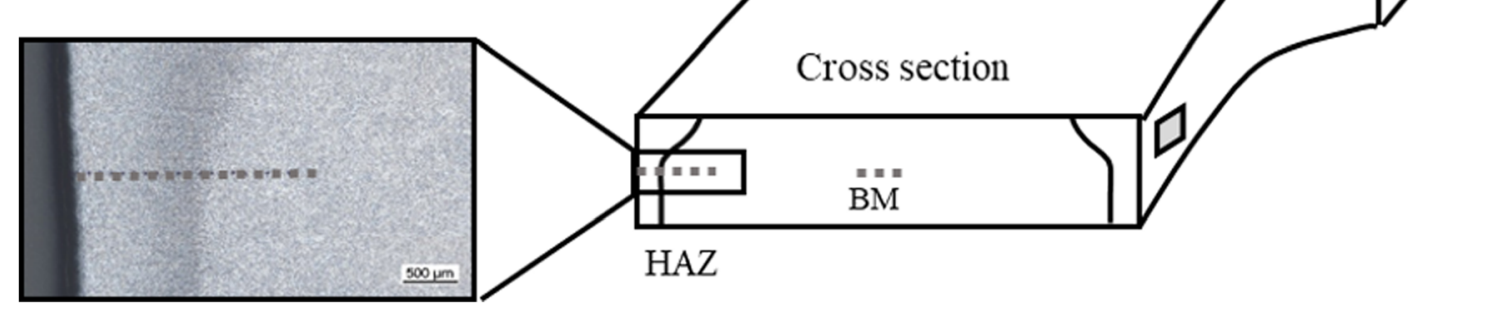

Fig. 3 Location of measurements the quality characteristics

\section{Results}

\subsection{Roughness on the cut edge}

The measured roughness parameters on the cut edge are the average of the five highest peaks and lowest valleys $R_{\mathrm{z}}$, the arithmetical average $R_{\mathrm{a}}$, and the maximum peak to valley height $R_{\max }$. The results are summarized in Table 5. The corresponding roughness measurements and allowable ranges, according to ISO 9013, are shown in Fig. 5. It demonstrates the arithmetic mean of surface roughness $R_{\mathrm{a}}$ as a function of arithmetical peak-to-peak average roughness $R_{\mathrm{z}}$ for different cutting technologies and steel strengths (thickness $8 \mathrm{~mm}$ ). The different quality groups according to the ISO 9013 for 8-mm-thick plates are also shown on the top of the figure. The cutting technologies have various colors (red — oxygen, blue - plasma, green - laser, black - waterjet) and the cut edge condition is marked as a cycle (as-cut) or as a square (improved quality).

All measurements can be classified in range 2 and range 3 . Plasma cut edge specimens show the best quality of all cutting technologies, which defined in quality range 2 . Oxygen cut edge has a high scatter between ranges 2 and 3. For the laser and waterjet cut edges, the figure shows some differences. Depending on the cutting speed, two different qualities can be reached. For high cutting speed, the roughness is also high and the quality range is 3 . A reduction of the cutting speed increases the quality and the roughness is low $\left(R_{\mathrm{z}} 27-41\right.$, quality range 2$)$.

Shot peening and grinding do not change the roughness values compared with the as-cut conditions at the cut edge surface significantly, even though the shape of the cut edge looks visually smoother after posttreatment methods used (see Table 3).

Table 3 Cut surfaces of steel S355M condition as-cut and improved quality using oxygen, plasma, laser, and waterjet cutting processes

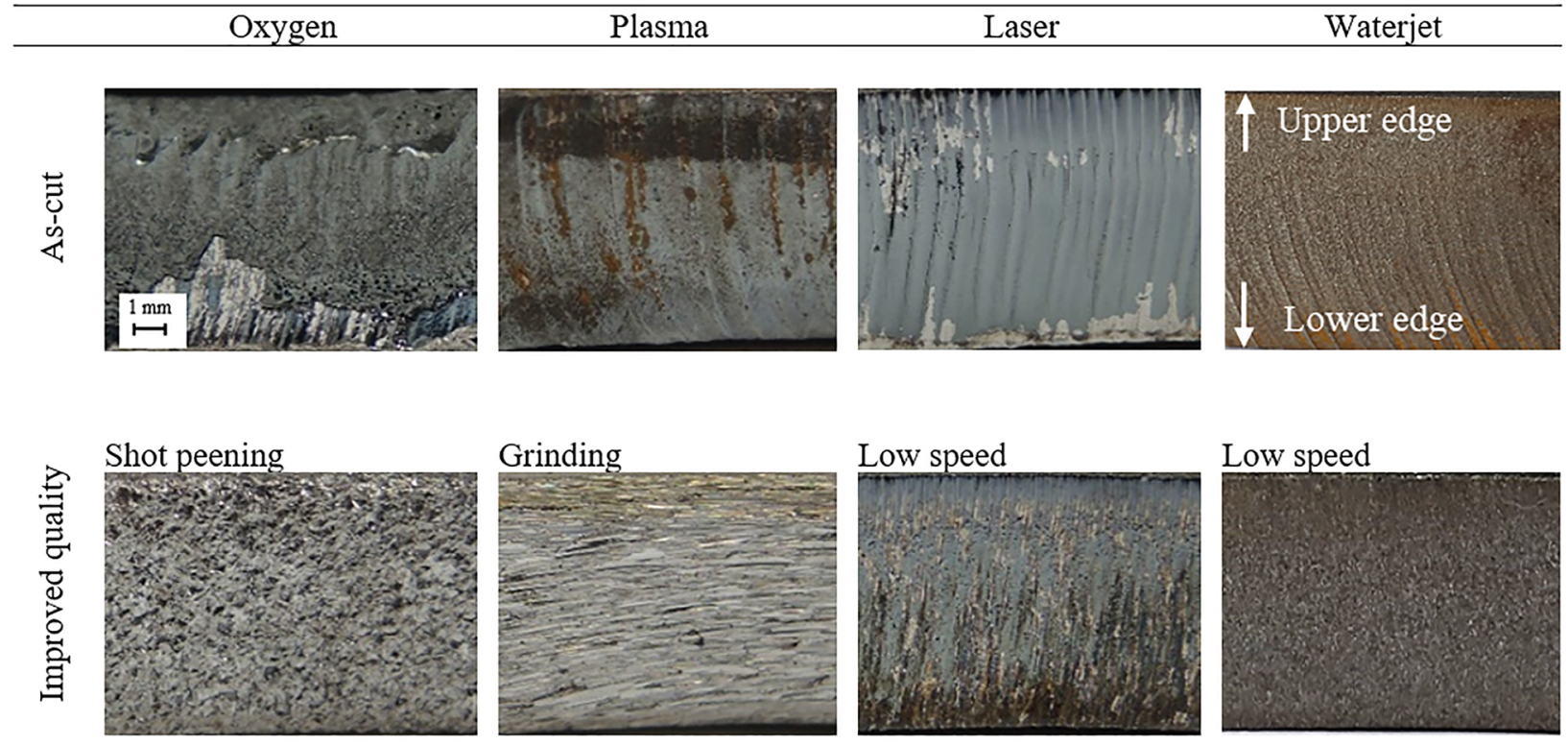



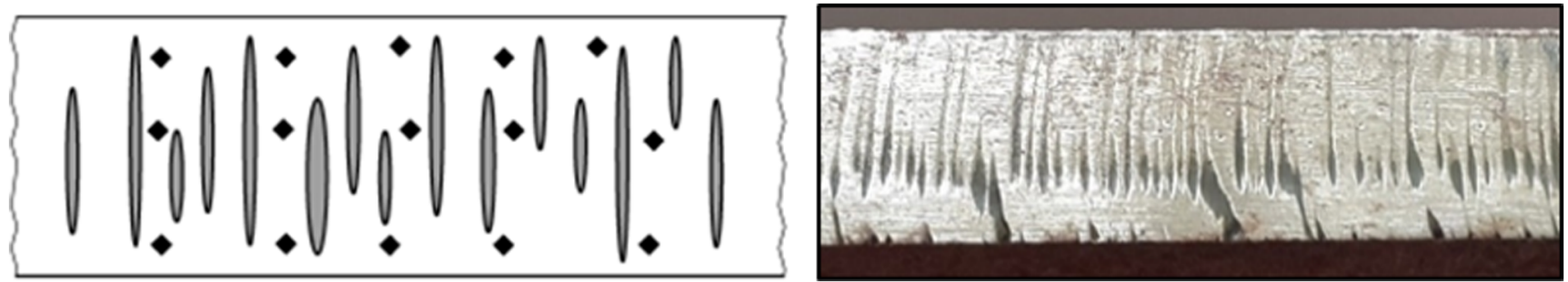

Fig. 4 Left: Location of measurements at the ground cut edge (schematically). Right: Ground cut edge

\subsection{Hardness measurements}

The various cutting technologies affect the material close to the cut edge, as shown schematically in Fig. 3. Cutting speeds related with the cooling rates have an influence on the size of the heataffected zone (HAZ). The CEV of the steel grades determine the possible maximum hardness. Figure 6 shows hardness measurements on the cross section for S355M, $8 \mathrm{~mm}$ and S690Q, $8 \mathrm{~mm}$. The curves are plotted just for thermal cutting technology oxygen, plasma, and laser condition as-cut. All measurements were done approx. $2 \mathrm{~mm}$ from both edges into the unaffected base material. Concerning the hardness measurements, the HAZ is less than $500 \mu \mathrm{m}$ wide. Higher strength steels coming up with higher CEV implicate higher hardness values at the thermally cut edges. Comparing the cutting processes, plasma cutting achieves the highest hardness value. No hardness increase is observed at the oxygen cut $\mathrm{S} 335 \mathrm{M}$. The rapid change in the hardness profile of 8-mm-thick plates indicates a very small heat-affected zone. Laser cut specimens have a small HAZ with only one hardness measurement point. Regardless of the steel grade, the maximum hardness value is between 200 HV0.1 and 510 HV0.1. It implicates a relatively increased hardening compared with the base material from 10 to $170 \%$. The results shown are comparable to previous work $[2,4,10]$.
Additionally the local hardness of the cut edges of all series tested is shown in Fig. 7. The hardness was measured directly at the cut edge. Due to the higher test load (HV10), the local hardness at the cut edge is smaller than the maximum on the cross section. Because of the thin hardened layer, the preparation of the cut edge may remove the HAZ a little bit. Shot peening and grinding do not change the hardness value. The cutting speed reduction increases the cooling rate and the local hardness at the cut edge decreases (laser cut edges).

\subsection{Residual stress}

The residual stresses on the cut edge for the different cutting technologies and materials used are given in Fig. 8. It was measured parallel to the loading direction. Measurement results are very different. Waterjet cut edges show compressive residual stresses over the cut edge about $-200 \mathrm{MPa}$. The shot peened surface shows compressive residual stresses also, approx. - $200 \mathrm{MPa}$. Oxygen cut high-strength steels, all plasma and laser cut edges show tensile residual stress. Compressive stress on oxygen cut edges and on waterjet cut edges was also seen in [3]. They measured tensile residual stress just on plasma and not on laser cut edges. Remes et al. as well as Lillemäe

Table 4 Fatigue test program

\begin{tabular}{|c|c|c|c|c|c|c|}
\hline No. & Steel grade & Cutting process (treatment): cutting speed $(\mathrm{m} / \mathrm{min})$ & $t(\mathrm{~mm})$ & Stress ratio & Test type & Specimens tested \\
\hline 1 & S355M & Oxygen: 0.60 & 8 & 0.1 & CAL & 12 \\
\hline 2 & S355M & Oxygen (shot peening): 0.60 & 8 & 0.1 & CAL & 14 \\
\hline 3 & S355M & Plasma: 3.42 & 8 & 0.1 & CAL & 13 \\
\hline 4 & S355M & Plasma (grinding): 3.42 & 8 & 0.1 & CAL & 13 \\
\hline 5 & S355M & Laser: 0.90 & 8 & 0.1 & CAL & 10 \\
\hline 6 & S355M & Laser (reduced speed): 1.10 & 8 & 0.1 & CAL & 9 \\
\hline 7 & S355M & Waterjet: 0.22 & 8 & 0.1 & CAL & 11 \\
\hline 8 & S355M & Waterjet (reduced speed): 0.07 & 8 & 0.1 & CAL & 10 \\
\hline 9 & S690Q & Oxygen: 0.60 & 8 & 0.1 & CAL & 13 \\
\hline 10 & S690Q & Oxygen (grinding): 0.60 & 8 & 0.1 & CAL & 13 \\
\hline 11 & S690Q & Plasma: 3.42 & 8 & 0.1 & CAL & 9 \\
\hline 12 & S690Q & Laser: 0.90 & 8 & 0.1 & CAL & 13 \\
\hline 13 & S690Q & Laser (reduced speed): 1.10 & 8 & 0.1 & CAL & 12 \\
\hline 14 & S690Q & Waterjet: 0.22 & 8 & 0.1 & CAL & 11 \\
\hline 15 & S690Q & Waterjet (reduced speed): 0.07 & 8 & 0.1 & CAL & 13 \\
\hline
\end{tabular}


Table 5 Summary of cut edge surface roughness

\begin{tabular}{|c|c|c|c|c|c|}
\hline No. & Steel grade & Cutting process & $R_{\mathrm{Z}}$ (quality range) $(\mu \mathrm{m})$ & $R_{\mathrm{a}}(\mu \mathrm{m})$ & $R_{\max }(\mu \mathrm{m})$ \\
\hline 1 & $\mathrm{~S} 355 \mathrm{M}$ & Oxygen & $27-66(2-3)$ & $5-12$ & $40-76$ \\
\hline 2 & $\mathrm{~S} 355 \mathrm{M}$ & Oxygen (shot peening) & $43-62(3)$ & $7-11$ & $47-89$ \\
\hline 3 & $\mathrm{~S} 355 \mathrm{M}$ & Plasma & $17-35(2)$ & $3-6$ & $19-34$ \\
\hline 4 & $\mathrm{~S} 355 \mathrm{M}$ & Plasma (grinding) & $25-36(2)$ & $4-7$ & $33-58$ \\
\hline 5 & $\mathrm{~S} 355 \mathrm{M}$ & Laser & $60-73(3)$ & $11-14$ & $71-103$ \\
\hline 6 & $\mathrm{~S} 355 \mathrm{M}$ & Laser (reduced speed) & $33-41(2)$ & $4-5$ & $43-50$ \\
\hline 7 & $\mathrm{~S} 355 \mathrm{M}$ & Waterjet & $63-97(3-4)$ & $12-18$ & $76-129$ \\
\hline 8 & $\mathrm{~S} 355 \mathrm{M}$ & Waterjet (reduced speed) & 29-37 (2) & $4-5$ & $34-45$ \\
\hline 9 & S690Q & Oxygen & $22-51(2-3)$ & $4-9$ & $26-62$ \\
\hline 10 & S690Q & Oxygen (grinding) & $32-48(2-3)$ & $6-10$ & $44-64$ \\
\hline 11 & S690Q & Plasma & $18-27(2)$ & $4-7$ & $20-36$ \\
\hline 12 & S690Q & Laser & $46-70(3)$ & $9-13$ & 53-102 \\
\hline 13 & S690Q & Laser (reduced speed) & $27-37(2)$ & $5-6$ & $32-43$ \\
\hline 14 & S690Q & Waterjet & $58-73(3)$ & $11-14$ & $68-96$ \\
\hline 15 & S690Q & Waterjet (reduced speed) & $28-35(2)$ & $4-5$ & $32-45$ \\
\hline
\end{tabular}

show also only compressive stress in their investigation. No stress relaxation was observed due to surface grinding.

\subsection{Fatigue test results}

All fatigue test results are summarized in Table 6 including results from previous studies. It shows the number of specimens including run outs, the slope of the S-N curve, $\log \mathrm{C}$ (intercept of the S-N curve with the $y$-axis), the nominal fatigue strength $\Delta \sigma$ at 2 million load cycles $(\mathrm{POS}=50 \%$ ), the nominal fatigue strength $\Delta \sigma$ at 2 million load cycles (POS $=$ 97.7\%) with a $T_{\mathrm{s}} 1: 1.5$ according to Haibach, and the crack initiation location (cut edge/corner/plate surface).

The fatigue test results of all different series using oxygen, plasma, laser, and waterjet cutting technologies for various steel grades (S355M and S690Q) are shown in Figs. 9, 10,
Fig. 5 Arithmetic mean of surface roughness $R_{\mathrm{a}}$ as a function of arithmetical peak-to-peak average roughness $R_{\mathrm{z}}$ for different cutting technologies (S355M, $8 \mathrm{~mm}$ )

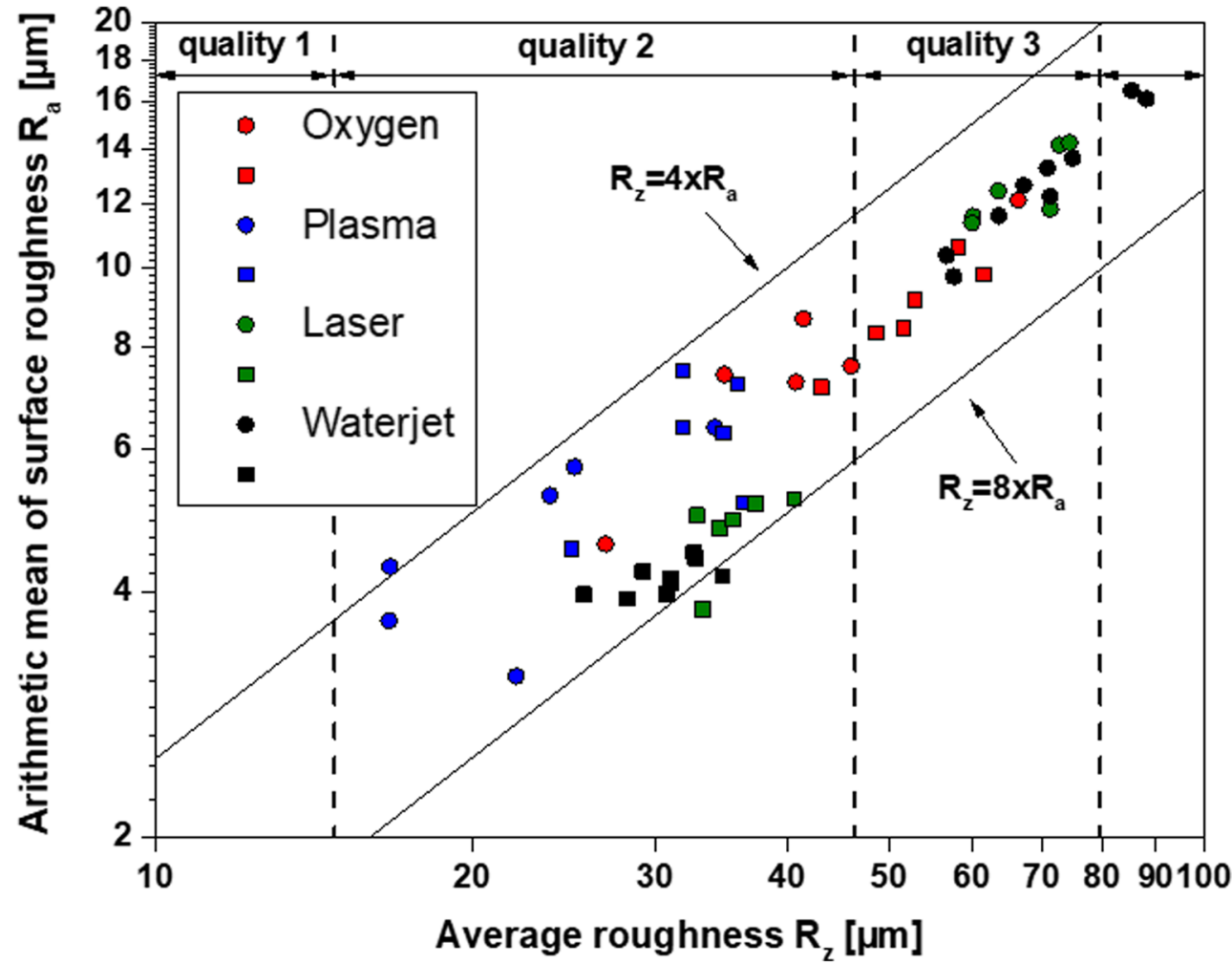



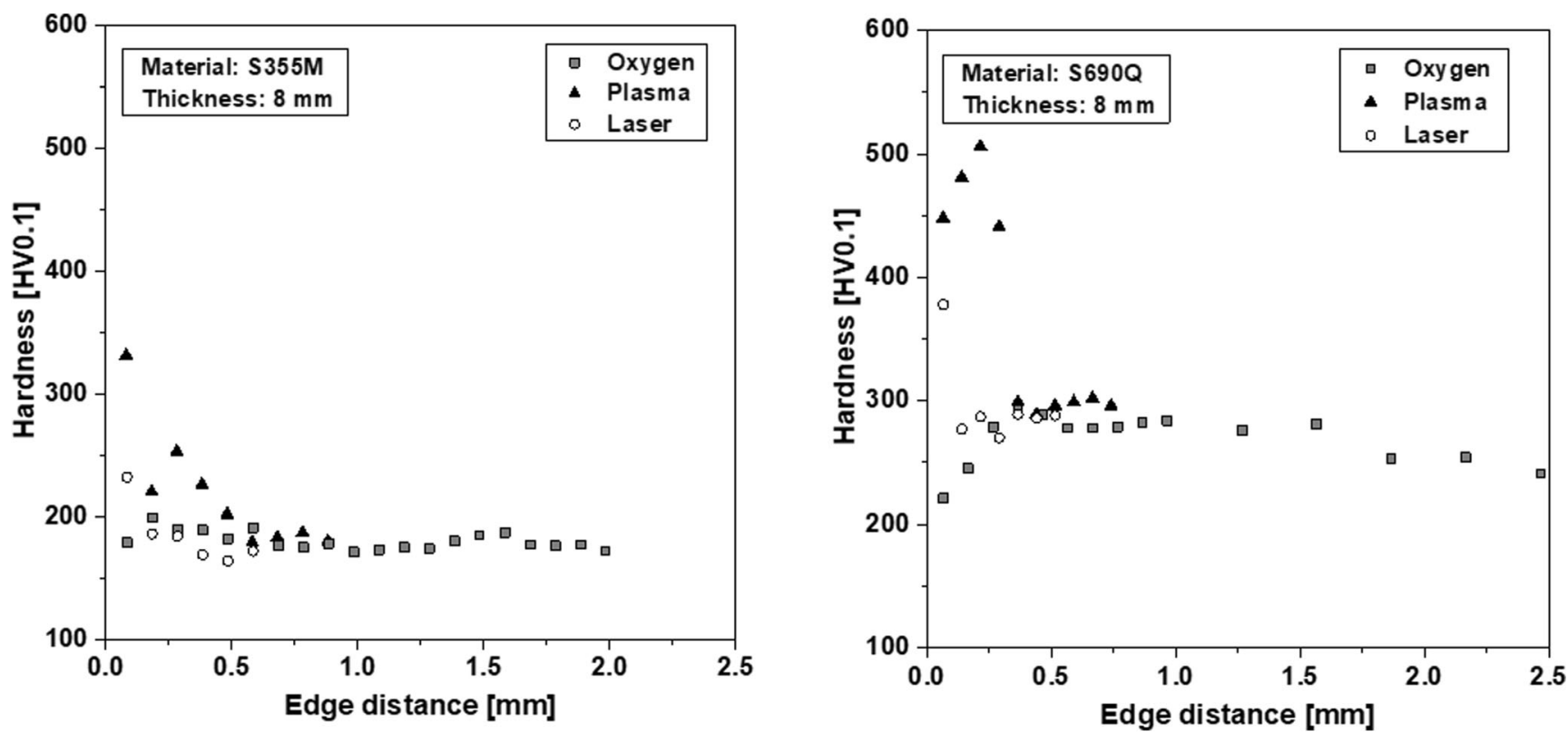

Fig. 6 Hardness measurements on the cross section of S355M $8 \mathrm{~mm}$ (left) and S690Q 8 mm (right) - oxygen, plasma, and laser cut specimens

11, and 12. Each figure presents one cutting technology with the different materials and quality improvement methods used. Two design curves from the IIW recommendations (FAT 125, FAT140) are also added.

Figure 9 shows the test data from oxygen cut specimens made from S355M and S690Q. The fatigue strength is sum up at the bottom left in the figure. The results show different fatigue strength and slopes. Specimens cut by oxygen cutting of S355M without using any posttreament method show a nominal fatigue strength range at 2 million load cyles of $\Delta \sigma=264 \mathrm{MPa}(\mathrm{POS}=50 \%)$. The regression line was calculated to $k=5.8$ without run outs including. The benefit of shot peening series is primary at higher numbers of load cycles. The fatigue strength increase was determined to $\Delta \sigma=$ $309 \mathrm{MPa}$ at 2 million load cycles with a flat slope of $k=9.8$, $117 \%$ increase of fatigue strength to the as-cut series. Short-

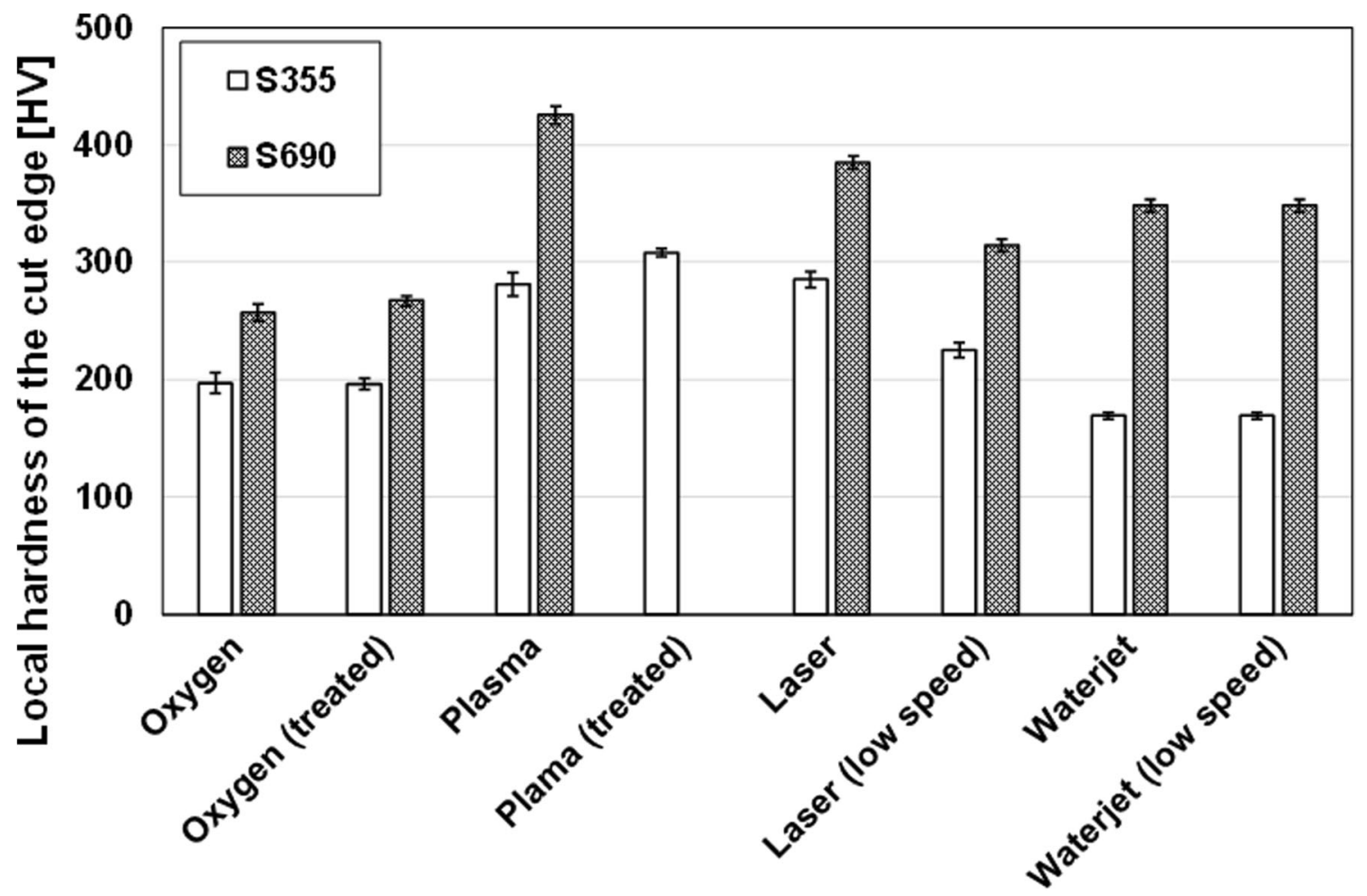

Fig. 7 Local hardness on the cut edge of all series tested 


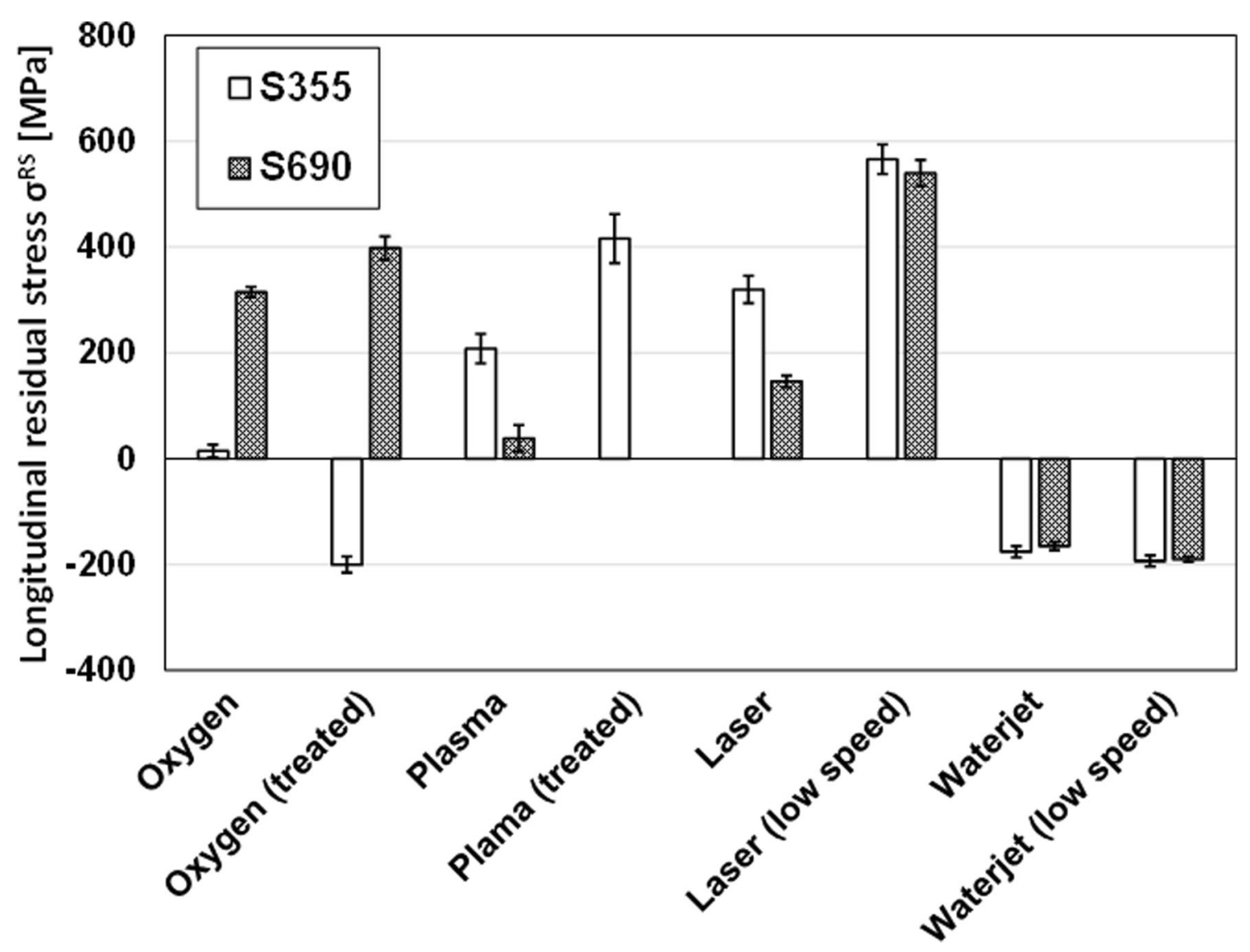

Fig. 8 Residual stress on the cut edge of all specimens tested

term strength of both series is comparable. No increase was observed using S690Q compared with S355M. Fatigue strength decreased to $\Delta \sigma=216 \mathrm{MPa}$. Contrary to the expectations, S690Q (ground) specimens show similar extrapolated fatigue strength results about $\Delta \sigma=208 \mathrm{MPa}$. Due to high number of load cycles at $\Delta \sigma \approx 400 \mathrm{MPa}$, the slope of $k$ gets very steep and the calculated fatigue limit down to $208 \mathrm{MPa}$. Even though run outs have a significant higher $\Delta \sigma$ of $288 \mathrm{MPa}$ compared with $\mathrm{S} 690$ (as-cut) specimens at $\Delta \sigma=216 \mathrm{MPa}$. The small amount of specimens especially for a high stress range could be one reason for it.

Test data from plasma cut specimens is shown in Fig. 10. Results of S355M specimens (as-cut) show fatigue strength at $\Delta \sigma=239 \mathrm{MPa}$ with a slope of $k=5$.2. A slight improvement of grinding the cut edge surface was observed. The fatigue strength was calculated to $\Delta \sigma=255 \mathrm{MPa}$ at 2 million load cycles with $k=5.2$. The benefit of using high-strength steels is most prominent at higher number of load cycles. Run outs have a significant higher stress range. But the fatigue strength was also calculated to a comparable level because of the steep slope $k=3.9(\Delta \sigma=232 \mathrm{MPa})$.

Fatigue test results of laser cut edges of 8-mm-thick specimens are illustrated in Fig. 11. For both materials, an increase of fatigue strength at 2 million load cycles was determined when the cutting speed is reduced. S355M $\Delta \sigma=300 \mathrm{MPa}$ (as-cut) $\rightarrow \Delta \sigma=338 \mathrm{MPa}$ (reduced speed) and S690Q $\Delta \sigma=$ $179 \mathrm{MPa} \rightarrow \Delta \sigma=209 \mathrm{MPa}$. The slopes of S335M S-N curves are significantly higher ( $k$ between 9.8 and 12.3) than the slopes of S690Q S-N curves ( $k$ between 3.0 and 3.4). It is also observed that the fatigue strength decreases for the highstrength steel. The cutting speed reduction leads to an improvement of the fatigue limits. One reason could be the geometrical improvement of the surface, despite the tensile residual stress on the cut edges.

The highest fatigue strength results were calculated for waterjet cut specimens. Figure 12 shows the test data from specimens made from S355M and S690Q with normal (ascut) and reduced cutting speed. The regression lines of all four S-N curves are very flat and the slopes are comparable $(k=$ 10.2-18.3). As well as the laser cut edges, waterjet cut edges show an increase of fatigue strength at 2 million load cycles using a reduced cutting speed. $\mathrm{S} 355 \mathrm{M} \Delta \sigma=351 \mathrm{MPa}$ (ascut) $\rightarrow \Delta \sigma=373 \mathrm{MPa}$ (reduced speed) and S690Q $\Delta \sigma=$ $449 \mathrm{MPa} \rightarrow \Delta \sigma=504 \mathrm{MPa}$. The effect of an increased fatigue strength using high-strength steels is seen.

A comparison of all various cutting technologies of $\mathrm{S} 355 \mathrm{M}$ specimens with a thickness of $8 \mathrm{~mm}$ is shown in Fig. 13. The plasma cut S-N curve shows the lowest fatigue strength $\Delta \sigma=$ $239 \mathrm{MPa}$ with $k=5.2$. Oxygen cut edges have a slightly higher fatigue strength level at $\Delta \sigma=264 \mathrm{MPa}$ with $k=5.8$. 


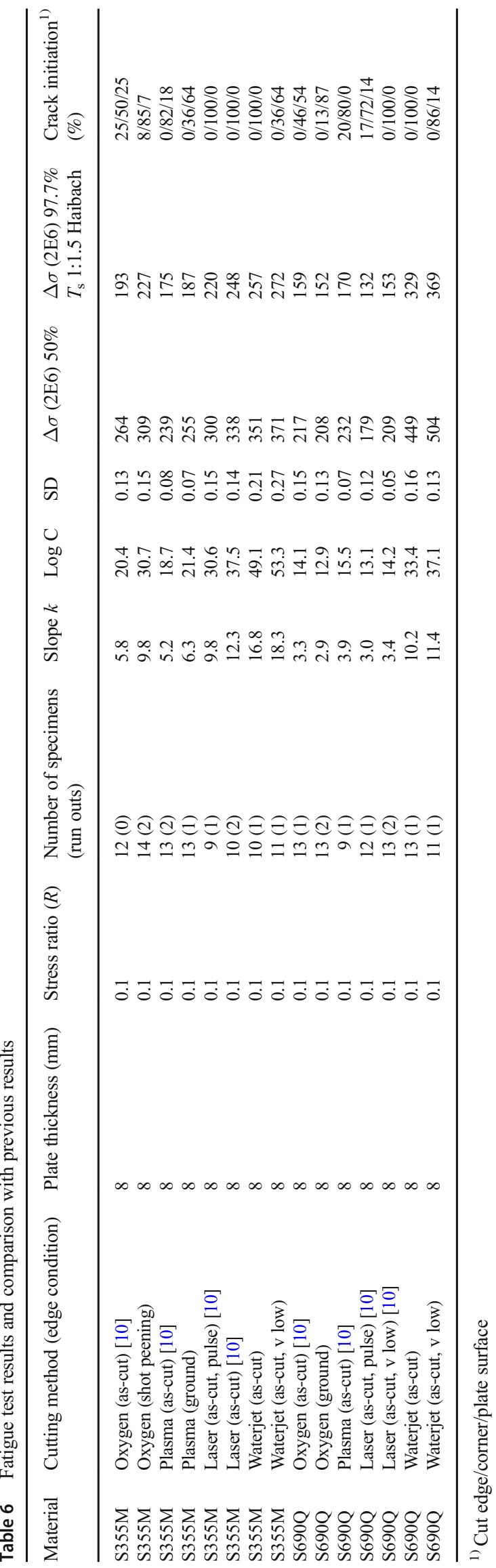

Laser cut edges have a fatigue strength at $\Delta \sigma=300$ with $k=$ 9.8 and the highest fatigue strength results were determined for waterjet cut edges at $\Delta \sigma=351 \mathrm{MPa}$ with a flat slope of $k=$ 16.8 .

The fracture surface analysis points out three different locations of crack initiation: on the cut edge, at the corner between cut edge and rolled plate surface, and at the plate surface. Figure 14 presents an example of each location of the crack initiation. In Table 6 , the percentage distribution of all the test specimens is summarized. The crack initiated mostly from the corner or even from the rolled plate surface (cf. [4]).

\section{Discussion}

This document investigated experimentally the influence of the quality characteristics according to ISO 9013 on the fatigue strength of thermal cut edges. Fatigue tests were conducted on thermal cut edges in different execution qualities with constant amplitude loads at a stress ratio $R=0.1$. Two different materials S355M and S690Q with a plate thickness of $8 \mathrm{~mm}$ were considered. The cutting methods used were oxy-fuel cutting, plasma cutting, laser cutting, and waterjet cutting. Quality improvement methods, like shot peening, grinding, and cutting speed reduction, were used. All samples were characterized in terms of hardness, roughness, and residual stresses.

Different fatigue strengths were determined for the cutting technologies and materials. Most of the specimens were tested "as-cut" without using any posttreatment method, like grinding or shot peening. Corners were not removed. For this cut edge surface quality, the IIW recommends FAT100. The investigation shows that all series exceed the FAT class and can be classified in FAT125. Specimens ranged in quality group 2 of ISO 9013 according to the roughness achieve FAT140 regardless of cutting technology or material.

The fatigue strength can be increased by quality improvement treatments. Shot peening as well as grinding on plasma cut edges shows higher fatigue strength. The treatment removed the defects on the surface and the corners. This is also shown in previous work (see, e.g., [2, 4]).

The cutting speed affects the roughness on the cut edge. Due to reduced cutting speeds, the roughness decreases also. This results in an increase of the fatigue strength in all tested series in this study (laser and waterjet cut edges). It also can be explained with in reduction of the defect on the cut edges.

Using waterjet cutting technologies, higher strength steels increase the fatigue strength. The roughness on the cut edge correlates with the fatigue strength and can be defined as the critical defect of the specimens. Waterjet cut edges show also the highest fatigue strength compared with the other cutting technologies. The defects are sufficiently small and the lifetime is governed by crack initiation. 


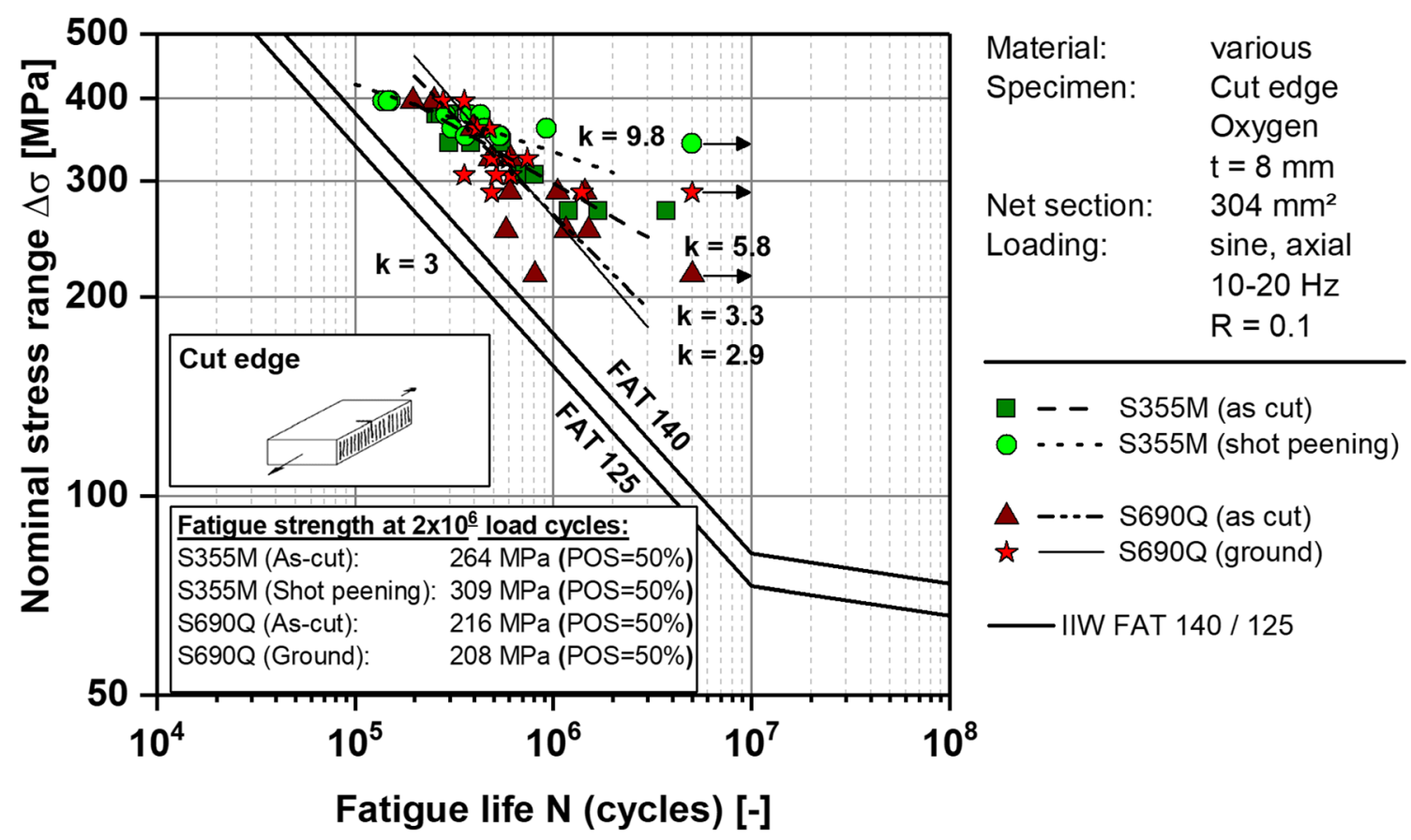

Fig. 9 Fatigue test results of oxygen cut edges, 8 -mm-thick specimen, stress ratio $R=0.1$. Shown here are test series 1 and 2 and 9 and 10

According to the roughness measurements on the cut edge surface, the plasma cut specimens were predicted to have the highest fatigue strength also shown in [3]. Fatigue test results show that they have the lowest fatigue strength level for S355M steels. The residual stress varied over all series. Waterjet cut specimens, shot peened specimens, and S355M oxygen cut edges show compressive stress or approx. zero. The positive influence of compressive stress for the fatigue strength was analyzed in previous studies already, e.g., [17]. Tensile residual stress was observed at S690Q oxygen cut edges as well as on all plasma and laser cut edges. Due to the stress ratio $R=0.1$ and the resulting high load, the influence of the tensile residual stress on the fatigue strength is low. However, the residual stress state, hardness, and the surface roughness should be considered. The surface condition in terms of surface roughness, hardness, and residual stress

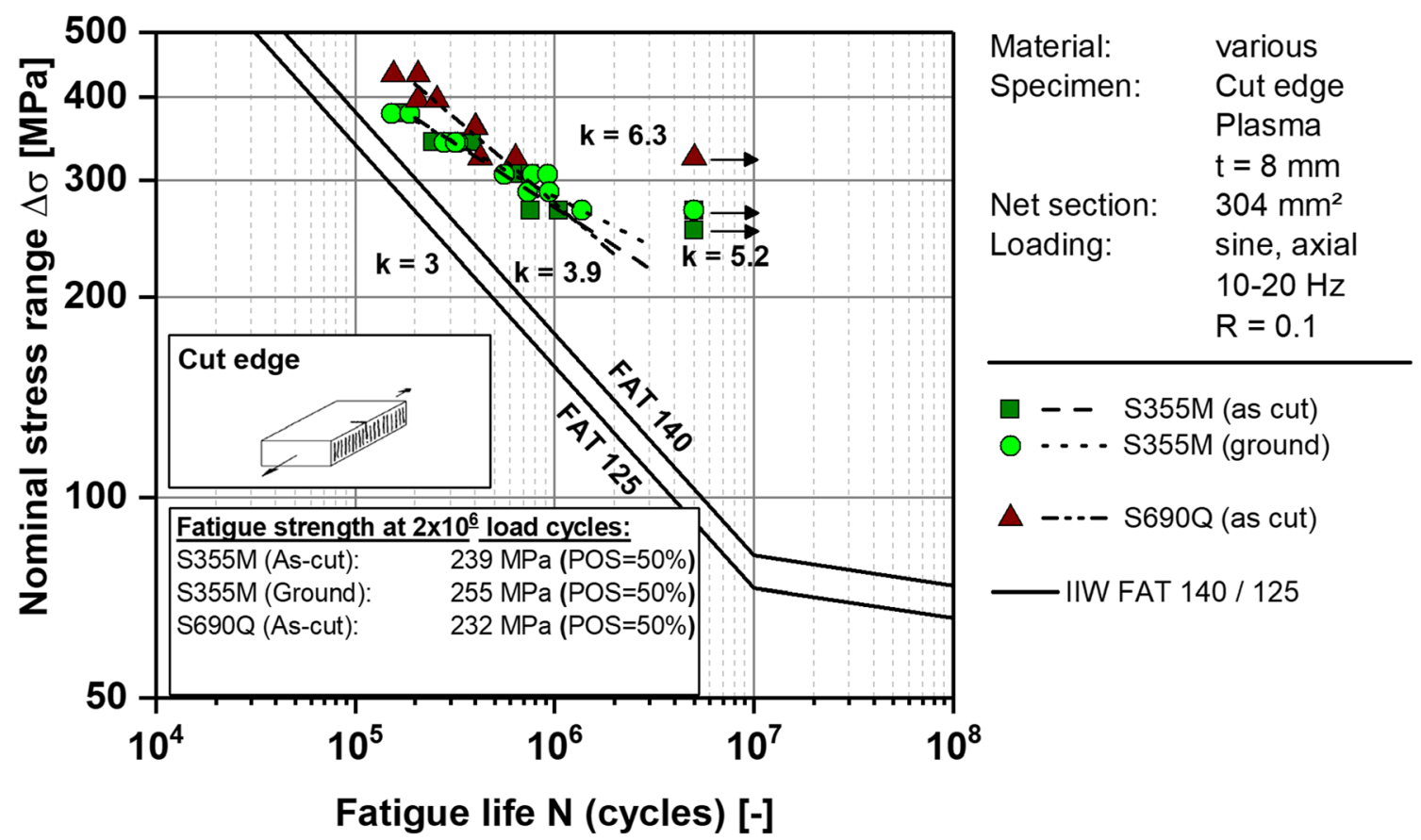

Fig. 10 Fatigue test results of plasma cut edges, 8 -mm-thick specimen, stress ratio $R=0.1$. Shown here are test series 3,4 , and 11 


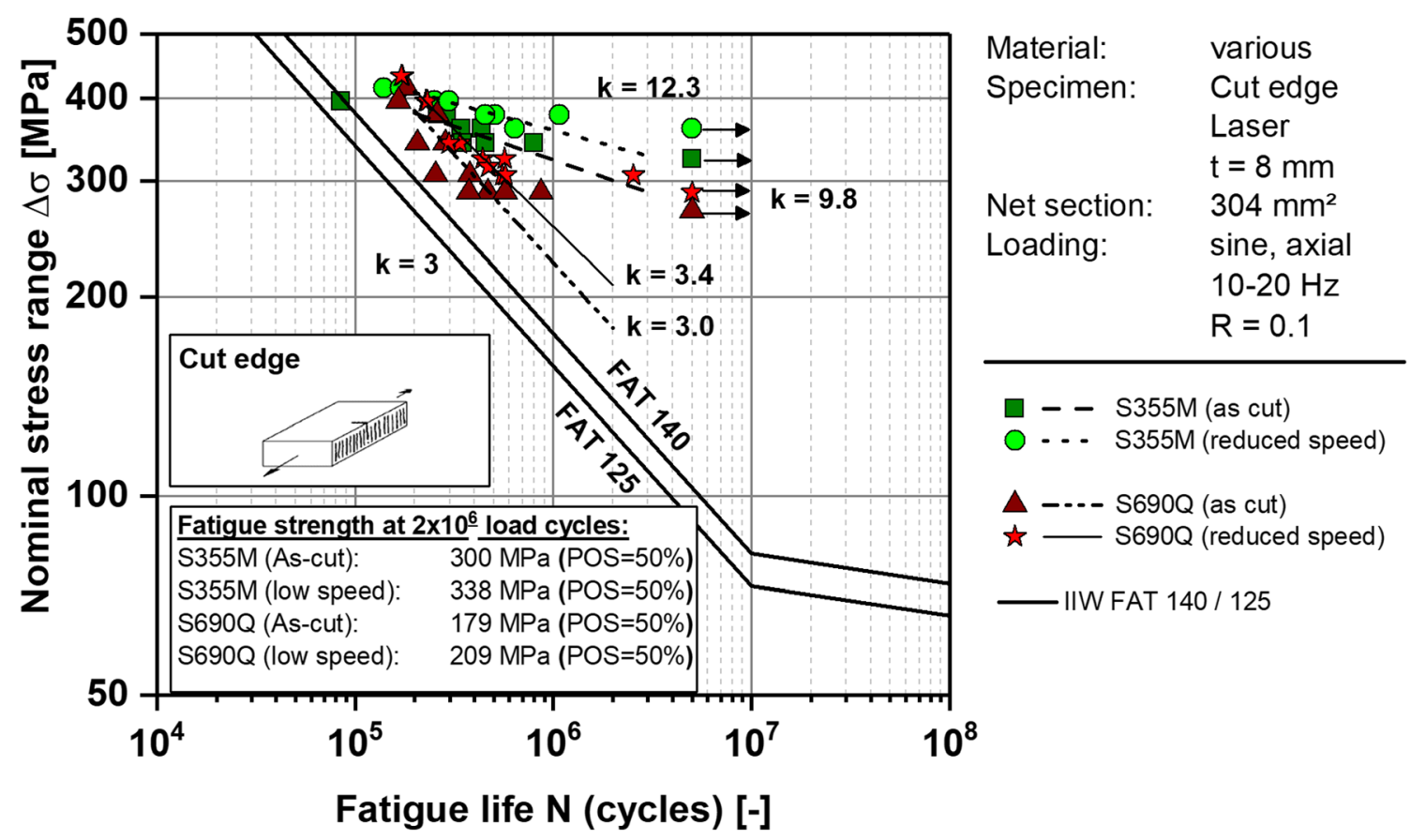

Fig. 11 Fatigue test results of laser cut edges, 8-mm-thick specimen, stress ratio $R=0.1$. Shown here are test series 5 and 6 and 12 and 13

changes depending on the cutting technology. ISO 9013 classifies the quality of the cut edges in four different groups. According to these quality groups, the ISO 9013 has a weak connection to fatigue strength, also seen in $[3,10]$. In order to make a prediction of the fatigue performance, the standard has to be specified and the cutting process as well as the steel strength should be considered. The fracture analysis shows that the crack initiates mostly from the corner. The location of crack initiation weakens the surface roughness as a critical quality characteristic and has to be considered. To modify the IIW recommendation for fatigue design, the ISO 9013 should be connected to it and waterjet cutting could be added in the standard. Different cutting methods reach different fatigue limits. Standards should cover that and should diversify cutting methods. A bonus factor could be considered using quality-enhancing methods.

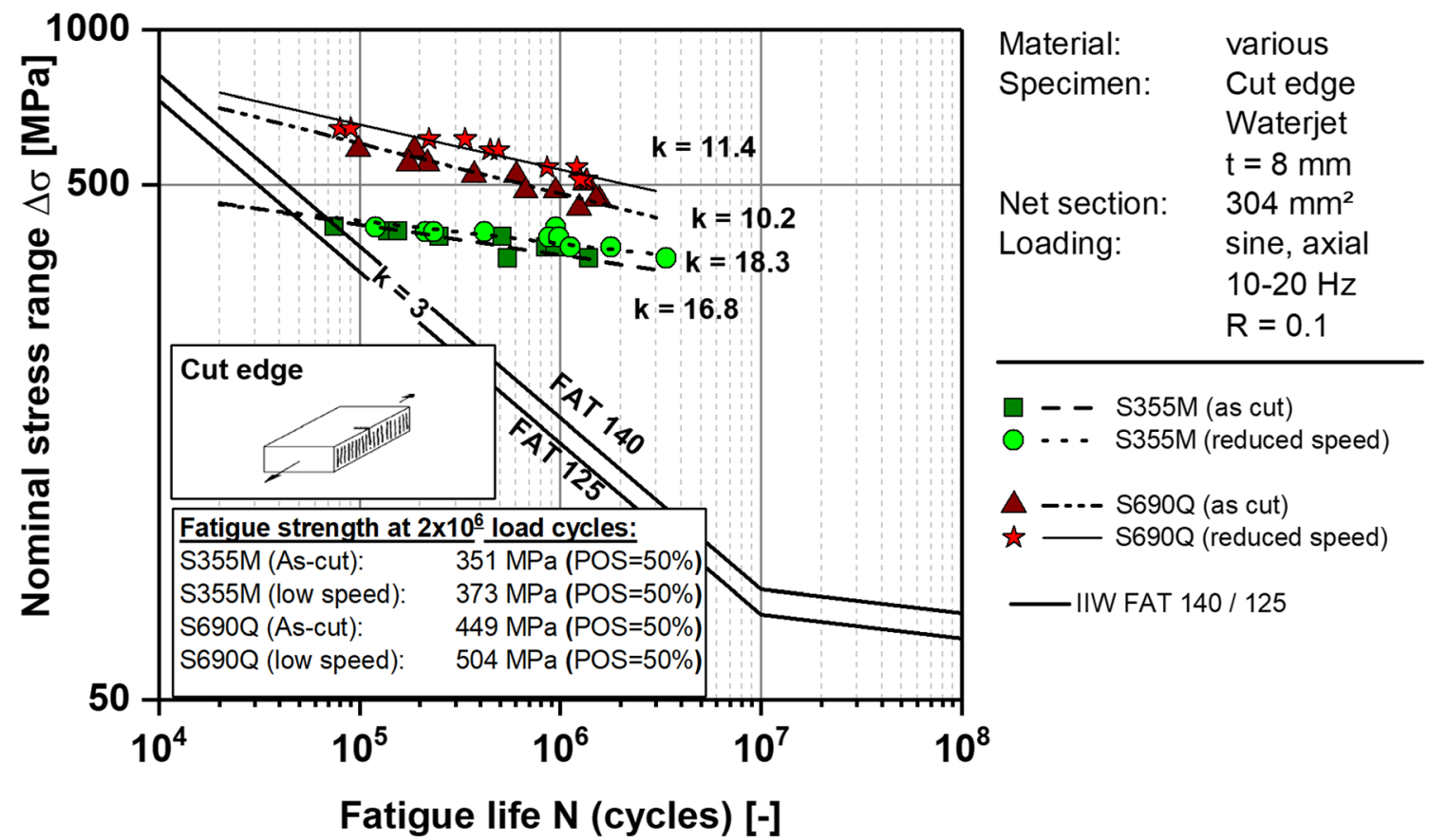

Fig. 12 Fatigue test results of waterjet cut edges, 8 -mm-thick specimen, stress ratio $R=0.1$. Shown here are test series 7 and 8 and 14 and 15 


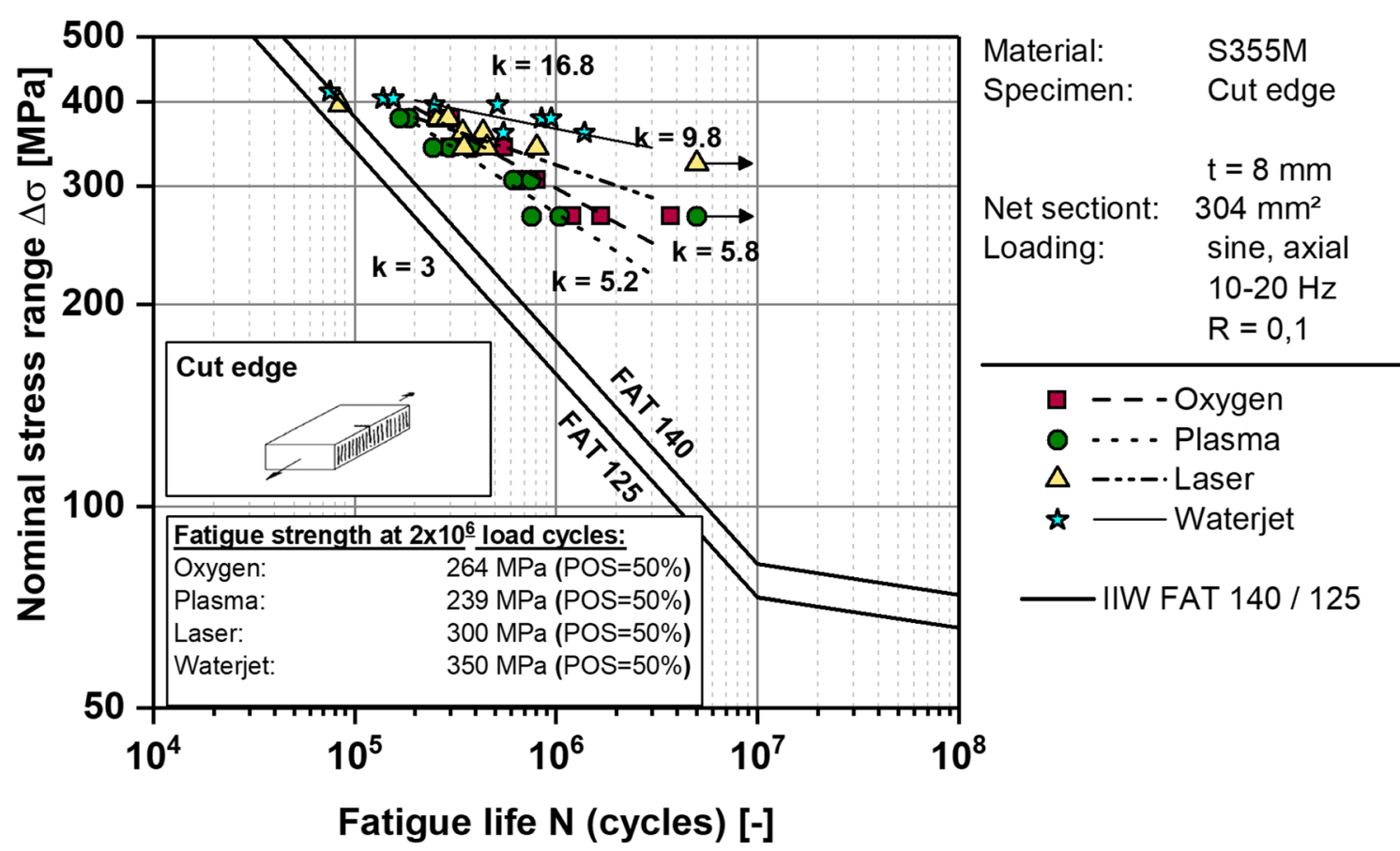

Fig. 13 Comparison of all various cutting technologies of S355M, 8 mm (as-cut)

\section{Summary}

In this investigation, fatigue tests were carried out on 8-mmthick samples with a minimum yield strength ranging from 355 to $690 \mathrm{MPa}$ at a stress ratio of $R=0.1$. The cutting methods used were oxygen, plasma, laser, and waterjet cutting. Quality improvement methods, like shot peening, grinding, and cutting speed reduction, were used. The surface roughness was measured to classify the specimens into quality groups according to ISO 9013. The cut edge condition was also characterized by hardness and residual stress measurements. The following conclusions can be made:

- Waterjet cutting technologies have the highest fatigue strength. High-strength steels increases the fatigue strength.

- The investigation shows that all tested series exceed the FAT100 class and can be classified in FAT125. Specimens ranged in quality group 2 of DIN EN ISO 9013 according to the roughness achieve
FAT140 regardless of cutting technology or material.

- According to the ISO 9013, most of the specimens are classified in the quality group 2 . Fatigue strength results are significant different in one quality group. No prediction can be made. ISO 9013 has a weak connection to fatigue strength.

- Quality improvement methods have a significant influence on the fatigue strength and can increase it. Due to reduced cutting speeds, the roughness decreases also. This results in an increase of the fatigue strength in all tested series in this study.

- In order to make a prediction of the fatigue performance, the standard has to be specified and the cutting process as well as the steel strength should be considered.

Funding information Open Access funding provided by Projekt DEAL. The presented investigations were supported by the Arbeitsgemeinschaft industrieller Forschungsvereinigungen $(\mathrm{AiF})$ in the project $18.789 \mathrm{~N}$ "Bedeutung der Qualitätsmerkmale freier Schnittkanten nach DIN EN
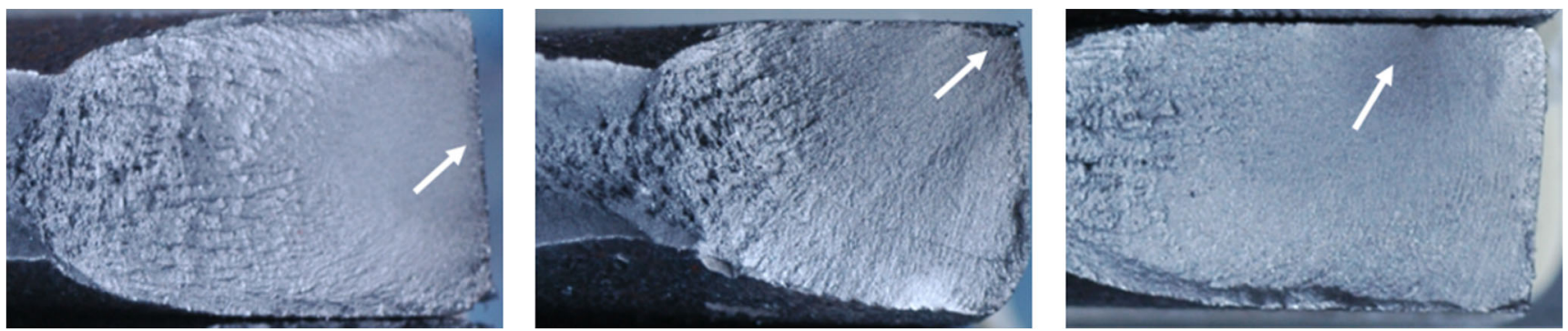

Fig. 14 Location of crack initiation (cut edge, corner, and plate surface) 
1090 für deren Schwingfestigkeit unter Berücksichtung von Eigenspannungen."

\section{Appendix. Raw data}

\begin{tabular}{llll}
\hline $\begin{array}{l}\text { Test specimen } \\
\text { (index) }\end{array}$ & $\begin{array}{l}\text { Load ratio } \\
(-)\end{array}$ & $\begin{array}{l}\text { Nominal stress range } \\
(\mathrm{MPa})\end{array}$ & $\begin{array}{l}\text { Fatigue life } \\
\text { (cycles) }\end{array}$ \\
\hline S355_A_8_01 & 0.1 & 378 & 257,488 \\
S355_A_8_02 & 0.1 & 378 & 271,009 \\
S355_A_8_03 & 0.1 & 378 & 301,023 \\
S355_A_8_04 & 0.1 & 342 & 299,207 \\
S355_A_8_05 & 0.1 & 342 & 552,562 \\
S355_A_8_06 & 0.1 & 342 & 386,736 \\
S355_A_8_07 & 0.1 & 306 & 687,346 \\
S355_A_8_08 & 0.1 & 306 & 718,035 \\
S355_A_8_09 & 0.1 & 306 & 803,485 \\
S355_A_8_10 & 0.1 & 270 & $1,681,284$ \\
S355_A_8_11 & 0.1 & 270 & $1,202,510$ \\
S355_A_8_12 & 0.1 & 270 & $3,720,270$ \\
\hline
\end{tabular}

\begin{tabular}{|c|c|c|c|}
\hline $\begin{array}{l}\text { Test specimen } \\
\text { (index) }\end{array}$ & $\begin{array}{l}\text { Load ratio } \\
(-)\end{array}$ & $\begin{array}{l}\text { Nominal stress range } \\
(\mathrm{MPa})\end{array}$ & $\begin{array}{l}\text { Fatigue life } \\
\text { (cycles) }\end{array}$ \\
\hline $\begin{array}{l}\text { S355_A_8 } \\
\text { KS_01* }\end{array}$ & 0.1 & 396 & 138,146 \\
\hline $\begin{array}{c}\text { S355_A } 8 \text { - } \\
\text { KS__02 }\end{array}$ & 0.1 & 396 & 151,297 \\
\hline $\begin{array}{l}\text { S355_A_ } 8 \\
\text { KS_03 }\end{array}$ & 0.1 & 396 & 146,810 \\
\hline $\begin{array}{c}\text { S355_A_8 } \\
\text { KS_04 }\end{array}$ & 0.1 & 378 & 288,027 \\
\hline $\begin{array}{c}\text { S355_A_8 } \\
\text { KS_05 }\end{array}$ & 0.1 & 378 & 380,530 \\
\hline $\begin{array}{c}\text { S355_A_ } 8 \\
\text { KS_06 }\end{array}$ & 0.1 & 378 & 430,683 \\
\hline $\begin{array}{c}\mathrm{S} 355_{-}^{-} \mathrm{A}-8 \\
\mathrm{KS} \_07\end{array}$ & 0.1 & 360 & 925,846 \\
\hline $\begin{array}{c}\text { S355_A_ } 8- \\
\text { KS_08 }\end{array}$ & 0.1 & 360 & 447,900 \\
\hline $\begin{array}{l}\text { S355_A_8 } \\
\text { KS_09 }\end{array}$ & 0.1 & 360 & 307,082 \\
\hline $\begin{array}{c}\mathrm{S} 355 \_\mathrm{A}-8 \\
\mathrm{KS} \_10\end{array}$ & 0.1 & 351 & 540,372 \\
\hline S355_A_8 & 0.1 & 351 & 535,480 \\
\hline $\begin{array}{c}\mathrm{S} 355 \_\mathrm{A} \_8 \\
\mathrm{KS} \_-12\end{array}$ & 0.1 & 351 & 360,241 \\
\hline $\begin{array}{c}\mathrm{S} 355 \_\mathrm{A} \_8 \\
\mathrm{KS} \_13\end{array}$ & 0.1 & 342 & $5,000,000$ \\
\hline
\end{tabular}

* KS shot peening

\begin{tabular}{llll}
\hline $\begin{array}{l}\text { Test specimen } \\
\text { (index) }\end{array}$ & $\begin{array}{l}\text { Load ratio } \\
(-)\end{array}$ & $\begin{array}{l}\text { Nominal stress range } \\
\text { (MPa) }\end{array}$ & $\begin{array}{l}\text { Fatigue life } \\
\text { (cycles) }\end{array}$ \\
\hline S355_P_8_01 & 0.1 & 378 & 186,313 \\
S355_P_8_02 & 0.1 & 378 & 167,733 \\
S355_P_8_03 & 0.1 & 378 & 168,848 \\
S355_P_8_04 & 0.1 & 342 & 296,871 \\
S355_P_8_05 & 0.1 & 342 & 247,063 \\
S355_P_8_06 & 0.1 & 342 & 386,192 \\
S355_P_8_07 & 0.1 & 306 & 679,047 \\
S355_P_8_08 & 0.1 & 306 & 749,810 \\
S355_P_8_09 & 0.1 & 306 & 619,227 \\
S355_P_8_10 & 0.1 & 270 & $5,000,000$ \\
S355_P_8_11 & 0.1 & 270 & 756,423 \\
S355_P_8_12 & 0.1 & 270 & $1,045,573$ \\
S355_P_8_13 & 0.1 & 252 & $5,000,000$ \\
\hline
\end{tabular}

\begin{tabular}{llll}
\hline Test specimen (index) & $\begin{array}{l}\text { Load } \\
\text { ratio }(-)\end{array}$ & $\begin{array}{l}\text { Nominal stress } \\
\text { range }(\mathrm{MPa})\end{array}$ & $\begin{array}{l}\text { Fatigue life } \\
\text { (cycles) }\end{array}$ \\
\hline S355_P_8_BS_01* & 0.1 & 306 & 773,460 \\
S355_P_8_BS_02 & 0.1 & 306 & 926,997 \\
S355_P_8_BS_03 & 0.1 & 306 & 558,913 \\
S355_P_8_BS_04 & 0.1 & 342 & 278,922 \\
S355_P_8_BS_05 & 0.1 & 342 & 327,980 \\
S355_P_8_BS_06 & 0.1 & 342 & 318,903 \\
S355_P_8_BS_07 & 0.1 & 288 & 943,909 \\
S355_P_8_BS_08 & 0.1 & 378 & 188,243 \\
S355_P_8_BS_09 & 0.1 & 378 & 151,811 \\
S355_P_8_BS_10 & 0.1 & 288 & 737,934 \\
S355_P_8_BS_11 & 0.1 & 270 & $1,377,966$ \\
S355_P_8_BS_12 & 0.1 & 270 & $5,000,000$ \\
S355_P_8_BS_13 & 0.1 & 270 & $5,000,000$ \\
\hline
\end{tabular}

$* B S$ grinding

\begin{tabular}{llll}
\hline $\begin{array}{l}\text { Test specimen } \\
\text { (index) }\end{array}$ & $\begin{array}{l}\text { Load ratio } \\
(-)\end{array}$ & $\begin{array}{l}\text { Nominal stress range } \\
(\mathrm{MPa})\end{array}$ & $\begin{array}{l}\text { Fatigue life } \\
\text { (cycles) }\end{array}$ \\
\hline S355_L_8_01 & 0.1 & 396 & 84,611 \\
S355_L_8_02 & 0.1 & 378 & 261,235 \\
S355_L_8_03 & 0.1 & 378 & 290,594 \\
S355_L_8_04 & 0.1 & 360 & 343,733 \\
S355_L_8_05 & 0.1 & 360 & 435,484 \\
S355_L_8_06 & 0.1 & 342 & 453,993 \\
S355_L_8_07 & 0.1 & 342 & 349,009 \\
S355_L_8_08 & 0.1 & 342 & 800,043 \\
S355_L_8_09 & 0.1 & 324 & $5,000,000$ \\
\hline
\end{tabular}




\begin{tabular}{llll}
\hline Test specimen (index) & $\begin{array}{l}\text { Load } \\
\text { ratio (-) }\end{array}$ & $\begin{array}{l}\text { Nominal stress } \\
\text { range (MPa) }\end{array}$ & $\begin{array}{l}\text { Fatigue life } \\
\text { (cycles) }\end{array}$ \\
\hline S355_L_8_V2_01 & 0.1 & 396 & 251,926 \\
S355_L_8_V2_02 & 0.1 & 396 & 297,990 \\
S355_L_8_V2_03 & 0.1 & 378 & 507,452 \\
S355_L_8_V2_04 & 0.1 & 378 & $1,077,419$ \\
S355_L_8_V2_05 & 0.1 & 378 & 454,739 \\
S355_L_8_V2_06 & 0.1 & 360 & $5,000,000$ \\
S355_L_8_V2_07 & 0.1 & 360 & 639,413 \\
S355_L_8_V2_08 & 0.1 & 360 & $5,000,000$ \\
S355_L_8_V2_09 & 0.1 & 414 & 139,400 \\
S355_L_8_V2_10 & 0.1 & 414 & 169,439 \\
\hline
\end{tabular}

\begin{tabular}{llll}
\hline $\begin{array}{l}\text { Test specimen } \\
\text { (index) }\end{array}$ & $\begin{array}{l}\text { Load ratio } \\
(-)\end{array}$ & $\begin{array}{l}\text { Nominal stress range } \\
(\mathrm{MPa})\end{array}$ & $\begin{array}{l}\text { Fatigue life } \\
\text { (cycles) }\end{array}$ \\
\hline S355_W_8_01 & 0.1 & 414 & 75,134 \\
S355_W_8_02 & 0.1 & 405 & 138,549 \\
S355_W_8_03 & 0.1 & 405 & 156,045 \\
S355_W_8_04 & 0.1 & 396 & 249,444 \\
S355_W_8_05 & 0.1 & 396 & 513,765 \\
S355_W_8_06 & 0.1 & 378 & 847,415 \\
S355_W_8_07 & 0.1 & 378 & 944,600 \\
S355_W_8_08 & 0.1 & 360 & $1,385,232$ \\
S355_W_8_09 & 0.1 & 360 & 547,707 \\
S355_W_8_10 & 0.1 & 342 & $5,000,000$ \\
\hline
\end{tabular}

\begin{tabular}{llll}
\hline $\begin{array}{l}\text { Test specimen } \\
\text { (index) }\end{array}$ & $\begin{array}{l}\text { Load } \\
\text { ratio (-) }\end{array}$ & $\begin{array}{l}\text { Nominal stress range } \\
\text { (MPa) }\end{array}$ & $\begin{array}{l}\text { Fatigue life } \\
\text { (cycles) }\end{array}$ \\
\hline S355_W_8_V2_01 & 0.1 & 414 & 988,300 \\
S355_W_8_V2_02 & 0.1 & 414 & 120,400 \\
S355_W_8_V2_03 & 0.1 & 405 & 213,213 \\
S355_W_8_V2_04 & 0.1 & 405 & 418,110 \\
S355_W_8_V2_05 & 0.1 & 405 & 235,155 \\
S355_W_8_V2_06 & 0.1 & 396 & 878,900 \\
S355_W_8_V2_07 & 0.1 & 396 & 983,403 \\
S355_W_8_V2_08 & 0.1 & 378 & $1,124,536$ \\
S355_W_8_V2_09 & 0.1 & 378 & $1,789,851$ \\
S355_W_8_V2_10 & 0.1 & 360 & $3,363,511$ \\
S355_W_8_V2_11 & 0.1 & 360 & $5,000,000 *$ \\
\hline
\end{tabular}

*Crack initiation at clamping point

\begin{tabular}{llll}
\hline $\begin{array}{l}\text { Test specimen } \\
\text { (index) }\end{array}$ & $\begin{array}{l}\text { Load } \\
\text { ratio (-) }\end{array}$ & $\begin{array}{l}\text { Nominal stress } \\
\text { range (MPa) }\end{array}$ & $\begin{array}{l}\text { Fatigue life } \\
\text { (cycles) }\end{array}$ \\
\hline S690_A_8_01 & 0.1 & 216 & $5,000,000$ \\
S690_A_8_02 & 0.1 & 216 & $816,354 *$ \\
S690_A_8_03 & 0.1 & 252 & 578,544 \\
S690_A_8_04 & 0.1 & 252 & $1,509,115$ \\
S690_A_8_05 & 0.1 & 252 & $1,158,973$ \\
S690_A_8_06 & 0.1 & 288 & $1,053,707$ \\
S690_A_8_07 & 0.1 & 288 & 605,269 \\
S690_A_8_08 & 0.1 & 288 & $1,442,738$ \\
S690_A_8_09 & 0.1 & 324 & 482,980 \\
S690_A_8_10 & 0.1 & 324 & 608,066 \\
S690_A_8_11 & 0.1 & 360 & 400,725 \\
S690_A_8_12 & 0.1 & 360 & 391,707 \\
S690_A_8_13 & 0.1 & 396 & 249,321 \\
S690_A_8_14 & 0.1 & 396 & 195,460 \\
\hline
\end{tabular}

\begin{tabular}{llll}
\hline Test specimen (index) & $\begin{array}{l}\text { Load } \\
\text { ratio (-) }\end{array}$ & $\begin{array}{l}\text { Nominal stress } \\
\text { range (MPa) }\end{array}$ & $\begin{array}{l}\text { Fatigue life } \\
\text { (cycles) }\end{array}$ \\
\hline S690_A_8_BS_01* & 0.1 & 306 & 355,484 \\
S690_A_8_BS_02 & 0.1 & 306 & 610,189 \\
S690_A_8_BS_03 & 0.1 & 306 & 516,488 \\
S690_A_8_BS_04 & 0.1 & 324 & 488,806 \\
S690_A_8_BS_05 & 0.1 & 324 & 738,990 \\
S690_A_8_BS_06 & 0.1 & 324 & 594,380 \\
S690_A_8_BS_07 & 0.1 & 360 & 477,455 \\
S690_A_8_BS_08 & 0.1 & 360 & 412,575 \\
S690_A_8_BS_09 & 0.1 & 396 & 354,714 \\
S690_A_8_BS_10 & 0.1 & 396 & 277,153 \\
S690_A_8_BS_11 & 0.1 & 288 & $1,392,654$ \\
S690_A_8_BS_12 & 0.1 & 288 & $5,000,000$ \\
S690_A_8_BS_13 & 0.1 & 288 & $5,000,000$ \\
\hline
\end{tabular}

*BS grinding

\begin{tabular}{llll}
\hline $\begin{array}{l}\text { Test specimen } \\
\text { (index) }\end{array}$ & $\begin{array}{l}\text { Load ratio } \\
(-)\end{array}$ & $\begin{array}{l}\text { Nominal stress range } \\
(\mathrm{MPa})\end{array}$ & $\begin{array}{l}\text { Fatigue life } \\
\text { (cycles) }\end{array}$ \\
\hline S690_P_8_01 & 0.1 & 324 & $5,000,000$ \\
S690_P_8_02 & 0.1 & 324 & 637,048 \\
S690_P_8_03 & 0.1 & 324 & 422,821 \\
S690_P_8_04 & 0.1 & 360 & 403,119 \\
S690_P_8_05 & 0.1 & 360 & 399,922 \\
S690_P_8_06 & 0.1 & 396 & 205,484 \\
S690_P_8_07 & 0.1 & 396 & 257,007 \\
S690_P_8_08 & 0.1 & 432 & 206,687 \\
S690_P_8_09 & 0.1 & 432 & 155,691 \\
\hline
\end{tabular}




\begin{tabular}{llll}
\hline $\begin{array}{l}\text { Test specimen } \\
\text { (index) }\end{array}$ & $\begin{array}{l}\text { Load ratio } \\
(-)\end{array}$ & $\begin{array}{l}\text { Nominal stress range } \\
(\mathrm{MPa})\end{array}$ & $\begin{array}{l}\text { Fatigue life } \\
\text { (cycles) }\end{array}$ \\
\hline S690_L_8_01 & 0.1 & 414 & 182,510 \\
S690_L_8_02 & 0.1 & 396 & 165,485 \\
S690_L_8_03 & 0.1 & 378 & 258,820 \\
S690_L_8_04 & 0.1 & 342 & 285,534 \\
S690_L_8_05 & 0.1 & 342 & 206,053 \\
S690_L_8_06 & 0.1 & 306 & 254,324 \\
S690_L_8_07 & 0.1 & 306 & 379,815 \\
S690_L_8_08 & 0.1 & 288 & 468,418 \\
S690_L_8_09 & 0.1 & 288 & 374,260 \\
S690_L_8_10 & 0.1 & 288 & 569,652 \\
S690_L_8_11 & 0.1 & 288 & 865,773 \\
S690_L_8_12 & 0.1 & 270 & $5,000,000$ \\
\hline
\end{tabular}

\begin{tabular}{llll}
\hline $\begin{array}{l}\text { Test specimen } \\
\text { (index) }\end{array}$ & $\begin{array}{l}\text { Load } \\
\text { ratio (-) }\end{array}$ & $\begin{array}{l}\text { Nominal stress } \\
\text { range (MPa) }\end{array}$ & $\begin{array}{l}\text { Fatigue life } \\
\text { (cycles) }\end{array}$ \\
\hline S690_W_8_V2_01 & 0.1 & 541 & $1,206,494$ \\
S690_W_8_V2_02 & 0.1 & 585 & 445,840 \\
S690_W_8_V2_03 & 0.1 & 585 & 490,581 \\
S690_W_8_V2_04 & 0.1 & 614 & 221,512 \\
S690_W_8_V2_05 & 0.1 & 614 & 336,094 \\
S690_W_8_V2_06 & 0.1 & 512 & $1,354,335$ \\
S690_W_8_V2_07 & 0.1 & 512 & $1,256,437$ \\
S690_W_8_V2_08 & 0.1 & 541 & 857,617 \\
S690_W_8_V2_09 & 0.1 & 643 & 79,508 \\
S690_W_8_V2_10 & 0.1 & 643 & 90,348 \\
S690_W_8_V2_11 & 0.1 & 512 & $5,000,000$ \\
\hline
\end{tabular}

Test specimen (index)

$(-)$

0.1

S690_L_8_V2_02 0.1

S690_L_8_V2_03 0.1

S690_L_8_V2_04 0.1

S690_L_8_V2_05 0.1

S690_L_8_V2_06 0

S690_L_8_V2_07 0 .

S690_L_8_V2_08 0.1

S690_L_8_V2_09 0.1

S690_L_8_V2_10 0.1

S690_L_8_V2_11 0.1

S690 L 8 V2 $12 \quad 0.1$
S690_L_8_V2_01 0.1

S690_L_8_V2 13 ad ratio Nominal stress range Fatigue life (MPa)

$\begin{array}{ll}432 & 173,579 \\ 432 & 171,234 \\ 396 & 227,804 \\ 396 & 231,498 \\ 342 & 337,710 \\ 342 & 297,959 \\ 324 & 439,918 \\ 324 & 568,368 \\ 315 & 471,126 \\ 306 & 553,959 \\ 306 & 574,489 \\ 306 & 2,539,532 * \\ 288 & 5,000,000\end{array}$

Open Access This article is licensed under a Creative Commons Attribution 4.0 International License, which permits use, sharing, adaptation, distribution and reproduction in any medium or format, as long as you give appropriate credit to the original author(s) and the source, provide a link to the Creative Commons licence, and indicate if changes were made. The images or other third party material in this article are included in the article's Creative Commons licence, unless indicated otherwise in a credit line to the material. If material is not included in the article's Creative Commons licence and your intended use is not permitted by statutory regulation or exceeds the permitted use, you will need to obtain permission directly from the copyright holder. To view a copy of this licence, visit http://creativecommons.org/licenses/by/4.0/.

\section{References}

1. Sperle J-O (2007) Influence of parent metal strength on the fatigue strength of parent material with machined and thermally cut edges. IIW Document XIII-2174-07. International Institute of Welding, Paris

\begin{tabular}{llll}
\hline $\begin{array}{l}\text { Test specimen } \\
\text { (index) }\end{array}$ & $\begin{array}{l}\text { Load ratio } \\
(-)\end{array}$ & $\begin{array}{l}\text { Nominal stress range } \\
\text { (MPa) }\end{array}$ & $\begin{array}{l}\text { Fatigue life } \\
\text { (cycles) }\end{array}$ \\
\hline S690_W_8_01 & 0.1 & 585 & 188,128 \\
S690_W_8_02 & 0.1 & 585 & 98,444 \\
S690_W_8_03 & 0.1 & 549 & 218,154 \\
S690_W_8_04 & 0.1 & 549 & 175,473 \\
S690_W_8_05 & 0.1 & 522 & 601,134 \\
S690_W_8_06 & 0.1 & 522 & 371,753 \\
S690_W_8_07 & 0.1 & 504 & $1,337,417$ \\
S690_W_8_08 & 0.1 & 486 & 947,814 \\
S690_W_8_09 & 0.1 & 486 & 672,357 \\
S690_W_8_10 & 0.1 & 468 & $1,559,374$ \\
S690_W_8_11 & 0.1 & 468 & $1,503,438$ \\
S690_W_8_12 & 0.1 & 450 & $1,240,000$ \\
S690_W_8_13 & 0.1 & 432 & $5,000,000$ \\
\hline
\end{tabular}

2. Remes H, Korhonen E, Lehto P, Romanoff J, Niemelä A, Hiltunen P, Kontkanen T (2013) Influence of surface integrity on the fatigue strength of high-strength steels. J Constr Steel Res 89(9):21-29

3. Stenberg T, Lindgren E, Barsoum Z, Barmicho I (2016) Fatigue assessment of cut edges in high strength steel - influence of surface quality. KTH Royal Institute of Technology

4. Lillemäe I, Liinalampi S, Lehtimäki E, Remes H, Lehto P, Romanoff J, Ehlers S, Niemelä A (2017) Fatigue strength of high strength steel after shipyard production process of plasma cutting, grinding and sandblasting, IIW Document XIII-2695-17. International Institute of Welding, Shanghai

5. DIN EN ISO 9013 (2002) Thermal cutting - classification of thermal cuts - geometrical product specification and quality tolerances. (ISO/DIS 9013:2014), Geneva

6. Hobbacher A (2009) IIW recommendations for fatigue design of welded joints and components WRC, vol 520. Welding Research Council Bulletin, WRC

7. European Standard (2005) Eurocode 3: design of steel structures part 1-9: Fatigue, EN 1003-1-9, Brussels, Belgium 
8. FKM-Richtlinie (2002) Rechnerischer Festigkeitsnachweis für Maschinenbauteile aus Stahl, Eisenguß- und Aluminiumwerkstoffe, 4. Ausgabe. VDMA-Verlag, Frankfurt/M

9. DIN EN 1090 (2017) Execution of steel structures and aluminum structures - part 2: technical requirements for steel structures; German and English version EN 1090-2

10. Diekhoff P, Hensel J, Nitschke-Pagel T, Dilger K (2019) Fatigue strength of thermal cut edges - influence of ISO 9013 quality groups. Welding in the World 63(2):349-363

11. DIN EN 10025-4 (2011) Hot rolled products of structural steels part 4: technical delivery conditions for thermomechanical rolled weldable fine grain structural steels; German version EN 10025-4

12. DIN EN 10025-5 (2011) Hot rolled products of structural steels part 5: technical delivery conditions for structural steels with improved atmospheric corrosion resistance; German version EN $10025-5$
13. DIN EN ISO 4288 (1998) Surface texture: profile method - rules and procedures for the assessment of surface texture. Beuth Verlag, Berlin

14. DIN EN ISO 6507-1 (2016) Metallic materials - Vickers hardness test - part 1: test method (ISO/DIS 6507-1:2016)

15. DIN 50159-1:2008 (2008) Metallische Werkstoffe - Härteprüfung nach dem UCI-Verfahren. Beuth Verlag, Berlin

16. DIN 50100 (2015) Load controlled fatigue testing - execution and evaluation of cyclic tests at constant load amplitudes on metallic specimens and components.

17. Thomas D, Whittaker M, Bright G, Gao Y (2011) The influence of mechanical and $\mathrm{CO} 2$ laser cut-edge characteristics on the fatigue life performance of high strength automotive steels. J Mat Process Technol Bd 211:263-274

Publisher's note Springer Nature remains neutral with regard to jurisdictional claims in published maps and institutional affiliations. 